\title{
Clinical Considerations When Initiating and Titrating Insulin Degludec/ Liraglutide (IDegLira) in People with Type 2 Diabetes
}

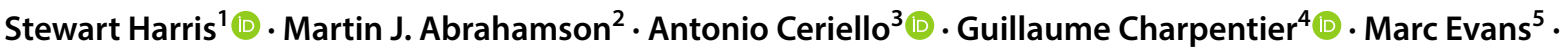

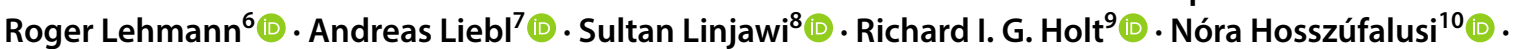 \\ Guy Rutten ${ }^{11}$ (D) Tina Vilsbø ${ }^{12}{ }^{10}$
}

Published online: 20 January 2020

(c) The Author(s) 2020

\begin{abstract}
Therapeutic inertia is a substantial obstacle to the initiation of insulin therapy in people with uncontrolled type 2 diabetes (T2D). This effect has in part been perpetuated by concerns over the impact of a burdensome regimen and the increased risk of hypoglycemia and body weight gain often associated with insulin use. An effective, yet simple, less burdensome regimen with a lower risk of body weight gain and hypoglycemia compared with an insulin-only regimen, may help to address these concerns more effectively. We review the available clinical and real-world data on IDegLira, a once-daily, injectable, fixedratio combination of insulin degludec (degludec) and the glucagon-like peptide-1 receptor agonist (GLP-1RA) liraglutide, in people with T2D. Evidence from the comprehensive DUAL clinical trial program suggests an advantage of IDegLira over traditional insulin therapies in a number of clinical outcomes, including maintenance of glycemic control, achievement of glycemic targets, reducing the risk of hypoglycemia, and body weight loss. These findings were demonstrated in participants with T2D irrespective of prior GLP-1RA and insulin use. Furthermore, the individual components of IDegLira have confirmed safety (degludec) or significant benefit in terms of improvement of cardiovascular risk (liraglutide). As an injectable therapy that is simple to titrate, IDegLira has the potential to optimize the ability to achieve relevant glycemic targets, and offers a suitable treatment option for people with T2D requiring insulin therapy who are at risk of hypoglycemia or weight gain.
\end{abstract}

\section{Key Points}

People with type 2 diabetes (T2D) and healthcare professionals can be reluctant to start insulin therapy.

IDegLira is a medicine that combines insulin with a glucagon-like peptide-1 receptor agonist, that can help people with T2D improve their blood sugar and reduce their risk of weight gain and hypoglycemia.

IDegLira allows for simple dose adjustment with a once daily injection, which combined with clinical benefits, may make it a more attractive option for those reluctant to start insulin.

Stewart Harris

Stewart.Harris@schulich.uwo.ca

Extended author information available on the last page of the article

\section{Introduction}

Type 2 diabetes (T2D) is a chronic, progressive disease with an etiology involving insulin resistance and progressive decline in $\beta$-cell function [1]. Current clinical practice guidelines recommend exercise and diet modification as the first-line therapy, alone or in combination with metformin. Treatment is intensified over time with the addition of further oral antidiabetes drugs (OADs) and/or injectable therapies, often in combination with each other [2,3].

Glucagon-like peptide-1 (GLP-1) receptor agonists (GLP1RAs) mimic naturally occurring GLP-1, a hormone secreted in response to food ingestion that enhances the release of endogenous insulin and suppresses endogenous glucagon secretion, both in a glucose-dependent manner. Both GLP1RA and basal insulin are recommended treatment options at many stages of T2D. These agents have complementary mechanisms of action, which, when used together, can offer several benefits to people with T2D [4, 5]. Basal insulin is effective at lowering glycated hemoglobin $\left(\mathrm{HbA}_{1 \mathrm{c}}\right)$ and fasting plasma glucose (FPG) levels, but increases the risk of hypoglycemia and 
body weight gain [4, 5]. Short-acting GLP-1RAs (exenatide, lixisenatide) lower postprandial glucose (PPG) when taken before a meal, whereas long-acting GLP-1RAs (dulaglutide, exenatide extended release, liraglutide, and semaglutide) lower both FPG and PPG; both act in a glucose-dependent manner. GLP-1RAs slow gastric emptying and increase satiety; however, GLP-1RAs can cause gastrointestinal (GI) adverse events, notably nausea and vomiting, especially in the early weeks of therapy. GLP-1RAs are suitable adjuncts to basal insulin as they can mitigate body weight gain and lower the risk of hypoglycemia since their co-use reduces the insulin dose requirement $[4,5]$. Therefore, the combination of these two therapies can be more effective yet better tolerated than basal insulin or GLP-1RA alone.

Co-formulations of oral therapies are well established, with many combinations of different drug classes currently available [6]. More recently, two injectable fixed-ratio combination (FRC) formulations of basal insulin and GLP-1RA have been approved [7]: IDegLira (first approved in the EU in 2014, and in the US in 2016) is a once-daily FRC of insulin degludec U100 (degludec) and the GLP-1RA liraglutide [8]; and IGlarLixi (approved in the US in 2016, and in the EU in 2017) is a once-daily FRC of insulin glargine U100 (IGlar U100) and lixisenatide (a GLP-1RA). Both IDegLira and IGlarLixi demonstrated either non-inferiority or superiority in $\mathrm{HbA}_{1 \mathrm{c}}$ reduction compared with their basal insulin and GLP-1RA components in monotherapy, respectively, in the DUAL I [8, 9] and LixiLan-O [10] trials.

The combination of an insulin and a GLP-1RA into one treatment simplifies therapy, halving the number of injections when compared with taking each component separately, and thereby reducing treatment burden [11]. Additionally, fewer GI adverse events are associated with FRCs of GLP-1RAs compared with the use of GLP-1RAs in free combination, as a result of a lower GLP-1RA starting dose and more gradual titration of the FRC, determined by the insulin component [12]. Furthermore, oral combination therapies have been shown to significantly improve treatment initiation and persistence compared with usual care [13]; this may also be applicable to injectable combination therapies. To support their use in clinical practice, clinicians need to be familiar with the initiation and titration of FRC products, and to identify suitable people who will benefit from this therapy [14].

This review focuses on the clinical evidence for one of the injectable FRCs, namely IDegLira, to explore its potential role in $\mathrm{T} 2 \mathrm{D}$ therapy.

\section{Unmet Clinical Need}

Reaching and maintaining personalized glycemic targets has been shown to improve outcomes in people with diabetes by reducing micro- and macrovascular complications
[15]. However, it is well established in clinical practice that people with diabetes often do not reach $\mathrm{HbA}_{1 \mathrm{c}}$ targets $[16,17]$ and that healthcare professionals (HCPs) can be reluctant to intensify therapy in a timely manner as recommended by clinical practice guidelines [3, 18, 19]. This phenomenon has been referred to as therapeutic inertia [20].

Therapeutic inertia, also called clinical inertia, can lead to delays in initiating insulin therapy in people with T2D with elevated $\mathrm{HbA}_{1 \mathrm{c}}$ levels [21-23]. Although significant improvements in glycemic control have been observed when insulin therapy was initiated in individuals not achieving $\mathrm{HbA}_{1 \mathrm{c}}$ targets with OADs alone, most people still did not achieve an $\mathrm{HbA}_{1 \mathrm{c}}$ target of $<7.0 \%(<53 \mathrm{mmol} / \mathrm{mol})$, even if this was their target level [22-24].

A number of reasons have been proposed for therapeutic inertia, such as HCPs being concerned about the impact of burdensome regimens on the quality of life of people with T2D, or their fears of causing people with T2D to experience hypoglycemia and body weight gain. It is important to recognize that therapeutic inertia might be the result of shared decision making, as people with diabetes are likely to share these concerns and may be reluctant to intensify their treatment [20].

A simple, less burdensome injectable therapy with a lower risk of body weight gain and hypoglycemia compared with an insulin-only regimen, requiring only a single daily injection, has the potential to reduce such concerns on the part of both HCPs and people with diabetes, thereby optimizing the ability to achieve relevant $\mathrm{HbA}_{1 \mathrm{c}}$ targets. Furthermore, by combining drugs with complementary actions, an FRC has the potential to provide more durable glycemic control. A durable therapy is defined as one that helps people with diabetes maintain glycemic control for longer and therefore require fewer intensification interventions compared with other treatment options. As a result of the chronic nature of T2D, a durable therapy could play an important role in preventing therapeutic inertia and minimizing chronic exposure to hyperglycemia. Additionally, the need for fewer interventions may lead to people with T2D feeling more positive about their disease management [25].

\section{Pharmacokinetic and Pharmacodynamic Properties of IDegLira and Its Constituents}

A one-unit dose (used in the US prescribing information) or dose step (used in the European Summary of Product Characteristics) of IDegLira comprises 1 unit of degludec and $0.036 \mathrm{mg}$ of liraglutide. IDegLira is administered oncedaily by subcutaneous injection, at any time of the day, but preferably at the same time each day [7]. 


\subsection{Pharmacokinetic and Pharmacodynamic Properties of Degludec}

Degludec is a long-acting, once-daily basal insulin. When injected, degludec forms a subcutaneous depot of multihexamers, from which monomers slowly and continuously dissociate [26]. It has a half-life of more than $25 \mathrm{~h}$ (compared with approximately $12 \mathrm{~h}$ for IGlar U100 and 5-7 h for insulin detemir), and provides a consistent and stable blood glucose-lowering profile over each 24 -h dosing interval [26-28], as well as relatively low day-to-day variability in the pharmacodynamic profile compared with other basal insulins $[29,30]$. The within-day variability in the glucoselowering effect of degludec has also been found to be lower by $40 \%$ and $37 \%$ compared with IGlar U100 and U300, respectively [30]. This reduction in glucose-lowering variability is likely to be associated with the significantly lower risk of overall hypoglycemia compared with IGlar U100, as demonstrated in the SWITCH [31, 32], DEVOTE [33], and BEGIN [34] trials. By contrast, morning administration of IGlar U300 0.4 units/kg/day in individuals with type 1 diabetes (T1D) provides less fluctuating 24-h pharmacodynamics and more even pharmacokinetic profiles compared with degludec 100 units/mL [35].

\subsection{Pharmacokinetic and Pharmacodynamic Properties of Liraglutide}

Liraglutide is a once-daily, injectable GLP-1RA, sharing 97\% sequence homology with human GLP-1 [36]. It is metabolized by dipeptidyl peptidase-4 (DPP-4) and neutral endopeptidase at a much slower rate than naturally occurring GLP-1 [37]. Absorption of liraglutide is slow (reaching maximum concentration $8-12 \mathrm{~h}$ after dosing) and the half-life is $13 \mathrm{~h}$, hence its suitability for once-daily dosing [36]. Liraglutide restores the $\beta$-cell insulin response, which is impaired in people with T2D, to levels similar to healthy individuals [38].

\subsection{Pharmacokinetic and Pharmacodynamic Properties of IDegLira}

The discrete pharmacokinetic properties of degludec and liraglutide are preserved when administered as the IDegLira co-formulation, with equivalence being demonstrated compared with both degludec and liraglutide monotherapy [39].

The maximum daily dose of IDegLira is $\mathbf{5 0}$ units/dose steps [7], as this delivers the maximum licenced liraglutide dose for diabetes of $1.8 \mathrm{mg}$ [36]. While there may be concern that the dose of degludec is capped at 50 units in IDegLira, the insulin requirement of people with T2D treated with IDegLira is greatly reduced as a result of the insulinsparing effect of liraglutide [40, 41].
4 Degludec and Liraglutide Clinical Trials

\subsection{Degludec Clinical Trials}

BEGIN $^{\circledR}$ was a phase III clinical trial program that investigated the efficacy and safety of degludec in more than 3000 people with T1D or T2D. It demonstrated degludec to be associated with a lower risk of hypoglycemia than IGlar U100 at the same $\mathrm{HbA}_{1 \mathrm{c}}$ level, and to offer more dosing flexibility [42-46]. Both insulin-naïve people [43-46] and those who had previously been treated with insulin $[42,43]$ were included. As these trials had a treat-to-target design, people treated with degludec achieved non-inferior reductions in $\mathrm{HbA}_{1 \mathrm{c}}$ compared with those treated with IGlar U100.

The total end-of-trial daily insulin dose was either similar in each treatment group [42, 43, 46] or statistically significantly lower (11-20\%) in participants receiving degludec compared with IGlar U100 in people with T2D $[44,45]$.

A preplanned meta-analysis of seven trials of degludec compared with IGlar U100 demonstrated that people with T2D treated with degludec experienced significantly lower rates of overall and nocturnal confirmed hypoglycemic episodes \{estimated rate ratios (ERRs) of 0.83 (95\% confidence intervals [CIs] $0.74 ; 0.94)$ and 0.68 (95\% CI $0.57 ; 0.82$ ), respectively [34]. The SWITCH 2 crossover trial confirmed that participants with T2D treated with degludec had significantly lower rates of overall and nocturnal confirmed hypoglycemia than people treated with IGlar U100 (ERR of 0.70 [95\% CI 0.61;0.80] and 0.58 [95\% CI 0.46; 0.74], respectively) [31]. The proportion of participants experiencing at least one severe episode of hypoglycemia was also lower with degludec (1.6\%) compared with IGlar U100 (2.4\%), but the difference did not reach significance [31]. SWITCH 2 demonstrated the safety of degludec in a high-risk population more reflective of everyday clinical practice as it enrolled participants who were at higher risk for hypoglycemia at baseline compared with the BEGIN trials, which had excluded participants with recurrent severe hypoglycemia or hypoglycemia unawareness.

\subsection{Liraglutide Clinical Trials}

The efficacy and safety of liraglutide either as monotherapy or in combination with OADs was investigated in more than 4000 people with T2D in the LEAD clinical trial program [47, 48]. LEAD demonstrated that the administration of liraglutide once-daily led to significantly superior improvements in $\mathrm{HbA}_{1 \mathrm{c}}$ compared with a variety of $\mathrm{OAD}$ 
comparators, with a low rate of hypoglycemia (lower than sulfonylureas and IGlar U100, but higher than placebo and rosiglitazone) and relative reductions in body weight compared with most comparators [49-54]. However, treatment with liraglutide and other GLP-1RAs resulted in an increased incidence of GI adverse events, although these tended to be transient, decreasing over time [49-55].

\section{Efficacy of Basal Insulin and GLP-1RA in Free Combination}

The complementary effects of free combinations of basal insulin and GLP-1RA therapy have been recognized for several years [56]. As an example, the BEGIN: ADD TO GLP-1 study investigated the efficacy and safety of administering degludec, compared with placebo, to people with T2D who had not achieved an $\mathrm{HbA}_{1 \mathrm{c}}$ target of $<7.0 \%$ $(<53 \mathrm{mmol} / \mathrm{mol})$ with metformin and maximum-dose liraglutide $(1.8 \mathrm{mg})$. After 26 weeks, $78 \%$ of participants receiving degludec had achieved $\mathrm{HbA}_{1 \mathrm{c}}<7.0 \%$ $(<53 \mathrm{mmol} / \mathrm{mol})$ compared with $36 \%$ of participants receiving placebo [57]. Another study investigated the effect of adding the basal insulin detemir to liraglutide and metformin in people with $\mathrm{T} 2 \mathrm{D}$ with $\mathrm{HbA}_{1 \mathrm{c}} \geq 7.0 \%$ ( $\geq 53 \mathrm{mmol} / \mathrm{mol}$ ), and reported that $43 \%$ of participants achieved an $\mathrm{HbA}_{1 \mathrm{c}}$ target of $<7.0 \%$ (53 mmol/mol) compared with $17 \%$ of participants receiving placebo [58].

A 26-week, double-blind, parallel-group, placebo-controlled study investigated the effect of adding liraglutide to a pre-existing basal insulin analogue \pm metformin in adults with inadequately controlled $\mathrm{T} 2 \mathrm{D}\left(\mathrm{HbA}_{1 \mathrm{c}} 7.0-10.0 \%\right.$ [53-86 mmol $/ \mathrm{mol}$ ]) [59]. After 26 weeks, 59\% and $43 \%$ of participants achieved $\mathrm{HbA}_{1 \mathrm{c}}<7.0 \%(53 \mathrm{mmol} / \mathrm{mol})$ or $\leq 6.5 \%$ ( $\leq 48 \mathrm{mmol} / \mathrm{mol})$ with liraglutide, respectively, compared with $14 \%$ and $4 \%$ of participants receiving placebo, respectively. Liraglutide also resulted in significantly improved body weight and systolic blood pressure compared with placebo [59].

A meta-analysis of 11 randomized controlled trials comparing free or fixed combinations of a GLP-1RA plus basal insulin with uptitration of basal insulin in people with $\mathrm{T} 2 \mathrm{D}$ reported that the combination therapy led to a mean $\mathrm{HbA}_{1 \mathrm{c}}$ decrease significantly greater than insulin uptitration $(-0.5 \%[-6 \mathrm{mmol} / \mathrm{mol}], 95 \% \mathrm{CI}-0.66$; $-0.40, p<0.001)$; more individuals at the $\mathrm{HbA}_{1 \mathrm{c}}$ target of $<7.0 \%$ (relative risk [RR] $1.69,95 \%$ CI $1.42 ; 2.00$, $p<0.001$ ); similar hypoglycemic events (RR $0.97,95 \%$ CI $0.84 ; 1.12, p=0.114)$; and reduction in body weight $(-1.9 \mathrm{~kg}, 95 \% \mathrm{CI}-2.3 ;-1.4, p<0.001)$. Results were consistent in both the free and fixed combination subgroups [60].

\section{IDegLira Clinical Trials}

The phase III, DUAL clinical trial program has demonstrated the efficacy and safety of IDegLira in participants with T2D irrespective of prior GLP-1RA and insulin use (Table 1). The primary endpoint for the DUAL I-VII and IX trials was change in $\mathrm{HbA}_{1 \mathrm{c}}$ from baseline to end of trial (EOT) (Fig. 1) [8, 40, 41, 61-65]. The key clinical findings from the DUAL program are summarized in Panel 1.

Panel 1: Key Clinical Learnings from the DUAL Program

- IDegLira provides reductions in $\mathrm{HbA}_{1 \mathrm{c}}$ to all patient groups with T2D regardless of their prior treatment (DUAL I-VII and IX)

- Despite this level of glucose-lowering efficacy, people randomized to IDegLira experienced fewer hypoglycemic episodes compared with those treated with basal or basal-bolus insulin therapy (DUAL I, II, V, VII, and IX)

- On average, people transferring from basal insulin to IDegLira experienced beneficial body weight reduction or stabilization, compared with people treated with continued basal or basal-bolus therapy (DUAL II, V and VII)

- IDegLira is associated with a lower incidence of GI adverse events compared with liraglutide or exenatide (DUAL I extension and DUAL III)

- IDegLira is an efficacious treatment option for people who do not achieve sufficient glycemic control with regimens containing sulfonylureas with or without metformin or basal insulin with or without metformin (DUAL IV, V and VII)

- Insulin-naïve people with T2D experienced greater durability of glycemic control when treated with IDegLira compared with IGlar U100 (DUAL VIII)

- IDegLira has a simple intensification regimen for people with T2D not reaching their glycemic targets on injectable therapy, as it enables intensification without additional daily injections (DUAL II, III, V, and VII)

- People switching to using IDegLira instead of adding bolus insulin to a basal insulin-based regimen can avoid the inconvenience of multiple daily insulin injections and reduce their total daily insulin dose in addition to benefiting from reductions in body weight and $\mathrm{HbA}_{1 \mathrm{c}}$ (DUAL VII)

$H b A_{l c}$, glycated hemoglobin, GI gastrointestinal, GLP-1RA glucagonlike peptide-1 receptor agonists, IDegLira insulin degludec/liraglutide, IGlar insulin glargine, $T 2 D$ type 2 diabetes

\subsection{Insulin-Naïve People Receiving Antidiabetes Drugs (OADs)}

Five trials investigated the efficacy and safety of IDegLira as an add-on to OADs, in people who were insulin-naïve with inadequate glycemic control (Table 1). 


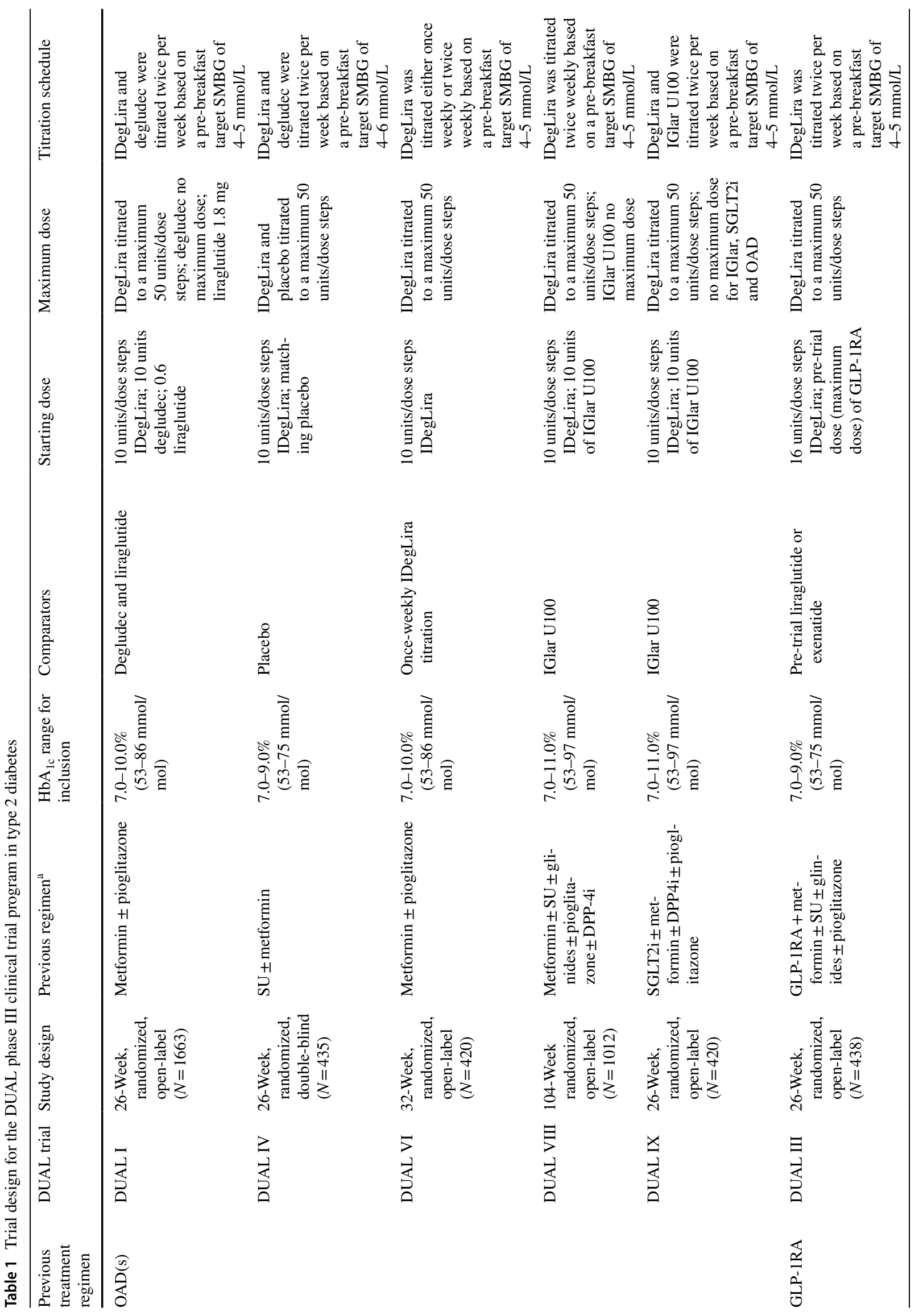




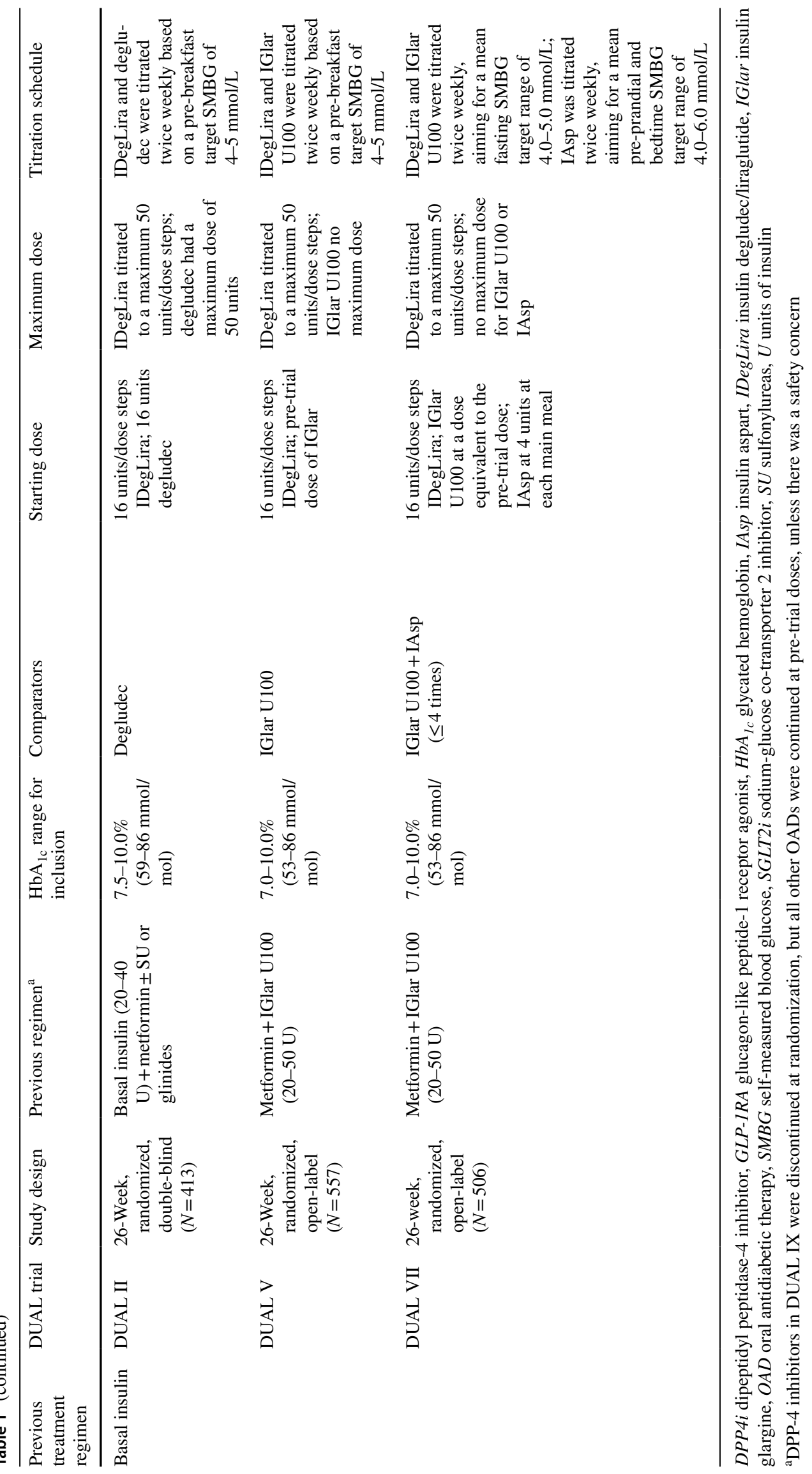




\subsubsection{DUAL I: IDegLira Compared with Both Degludec and Liraglutide}

DUAL I was a 26-week, randomized, open-label, parallel-group trial that compared the efficacy and safety of IDegLira with its components, degludec and liraglutide, in combination with metformin with or without pioglitazone (Table 1). IDegLira was found to be non-inferior to degludec and superior to liraglutide in reduction in $\mathrm{HbA}_{1 \mathrm{c}}$ from baseline to EOT (Fig. 1a). Participants treated with IDegLira experienced fewer episodes of hypoglycemia, body weight loss compared with body weight gain, and a lower insulin dose (Fig. 1b-d), but higher rates of GI adverse events when compared with participants treated with degludec (Table 2). Participants treated with IDegLira experienced more episodes of hypoglycemia and a reduced effect on weight loss (Fig. 1b, c), but with a lower rate of GI adverse events when compared with participants treated with liraglutide (Table 2) [8].

\subsubsection{DUAL IV: IDegLira Compared with Placebo}

DUAL IV was a 26-week, randomized, double-blind, parallel-group trial that assessed the efficacy and safety of IDegLira as an add-on to sulfonylurea therapy (Table 1). Mean reduction of $\mathrm{HbA}_{1 \mathrm{c}}$ from baseline was superior for participants who received IDegLira compared with placebo (Fig. 1a). The rate of confirmed hypoglycemia was higher with IDegLira than with placebo and the two events of severe hypoglycemia reported in the trial both occurred in the IDegLira treatment group $(n=289)$ (Fig. 1b). The rate of hypoglycemia observed with IDegLira in DUAL IV was higher than that observed in other trials in the DUAL program and may be attributed to the effect of sulfonylurea therapy, which is associated with an increased risk of hypoglycemia (and weight gain), especially when combined with insulin therapy. There was no significant difference in the rates of nocturnal hypoglycemia between the treatment groups. Participants treated with IDegLira experienced a body weight gain compared with a body weight loss with placebo (Fig. 1c) [63].

\subsubsection{DUAL VI: IDegLira Once-Weekly Compared with Twice-Weekly Titration}

DUAL VI was a 32-week, randomized, open-label, parallelgroup trial that assessed the efficacy and safety of IDegLira as an add-on to existing OAD therapy when titrated using a pragmatic once-weekly algorithm, compared with twice-weekly titration (Table 1), as recommended in current prescribing information [7,66]. Mean reduction in $\mathrm{HbA}_{1 \mathrm{c}}$ in the once-weekly titration group was non-inferior to twice-weekly titration (Fig. 1a). Participants in both the once- and twice-weekly titration arms experienced low rates of hypoglycemia (Fig. 1b) and were receiving the same dose of IDegLira at EOT (Fig. 1d). Participants who titrated IDegLira twice weekly achieved a significantly greater reduction in body weight compared with those who titrated IDegLira once weekly (Fig. 1c) [64].

\subsubsection{DUAL VIII: IDegLira Compared with IGlar U100}

DUAL VIII was a 104-week, open-label durability trial, comprising an initial 26 weeks where participants were titrated with either IDegLira or IGlar U100 to the $\mathrm{HbA}_{1 \mathrm{c}}$ target of $<7.0 \%(53 \mathrm{mmol} / \mathrm{mol})$, followed by 78 weeks of monitoring (Table 1). The primary endpoint was time from randomization to inadequate glycemic control and need for treatment intensification, defined as $\mathrm{HbA}_{1 \mathrm{c}} \geq 7.0 \%(53 \mathrm{mmol} /$ $\mathrm{mol}$ ) at two consecutive visits from week 26 (including week 26 if $\mathrm{HbA}_{1 \mathrm{c}}$ was $\geq 7.0 \%$ [53 $\left.\mathrm{mmol} / \mathrm{mol}\right]$ at week 12) up to 104 weeks. Participants treated with IDegLira had a longer time to 'need for treatment intensification' (median $>2$ years) compared with IGlar U100 (median approximately 1 year; $p<0.0001$ accounting for baseline $\mathrm{HbA}_{1 \mathrm{c}}$ group and background sulfonylurea use as baseline strata). Furthermore, $63 \%$ of participants treated with IDegLira did not require treatment intensification by week 104 compared with $34 \%$ of participants treated with IGlar U100. In addition to improved durability, participants in the IDegLira group also had a lower insulin dose (37 units compared with 52 units; estimated treatment difference [ETD] $-14.9 ; 95 \%$ CI - 17.4; $-12.5 ; p<0.0001)$, less body weight gain (1.7 compared with $3.4 \mathrm{~kg}$; ETD $-1.70 ; 95 \% \mathrm{CI}-2.47 ;-0.93 ; p<0.0001)$, and experienced a lower incidence of hypoglycemia $(0.38$ compared with 0.86 events per PYE; ERR 0.44; 95\% CI 0.33; $0.60 ; p<0.0001)$ than participants in the IGlar U100 group, had treatment intensification not been needed. No new safety signals were observed over the 2-year trial period [67].

\subsubsection{DUAL IX: IDegLira Compared with IGlar U100}

This 26-week, open-label trial aimed to investigate the efficacy and safety of IDegLira as an add-on to a sodiumglucose transport protein 2 inhibitor (Table 1). Participants treated with IDegLira achieved a superior reduction in mean $\mathrm{HbA}_{1 \mathrm{c}}$ from baseline to EOT compared with IGlar U100 (Fig. 1a). Participants in the IDegLira treatment arm experienced significantly lower rates of hypoglycemia and less body weight gain compared with IGlar U100 (Fig. 1b, c). At the end of the study, participants in the IDegLira arm were receiving a significantly lower mean daily insulin dose than participants treated with IGlar U100 (Fig. 1d) [65]. 


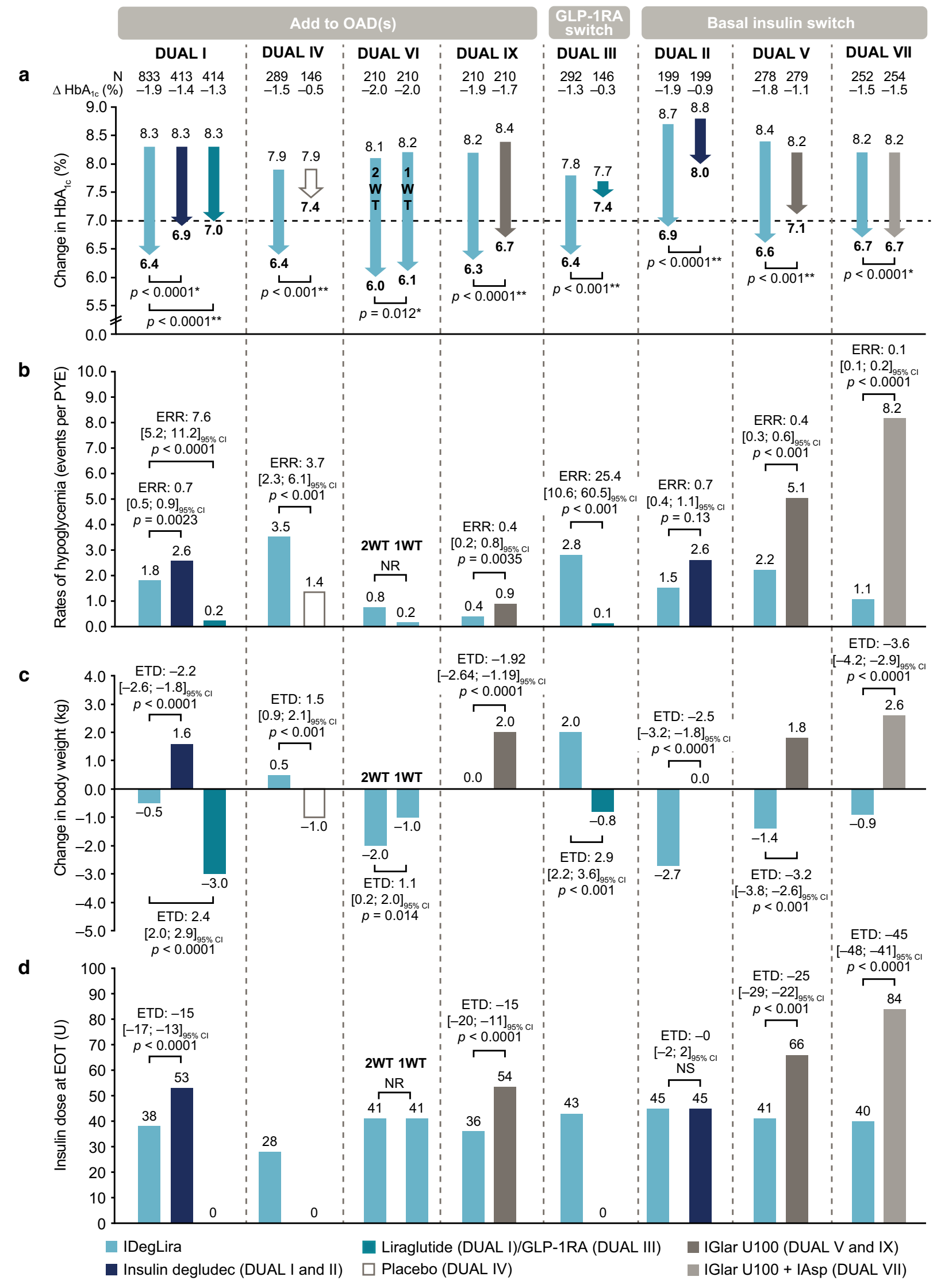


4 Fig. 1 Key findings from the DUAL program a change in $\mathrm{HbA}_{1 \mathrm{c}}$ at EOT; $\mathbf{b}$ rates of hypoglycemia; $\mathbf{c}$ change in body weight at EOT; and d insulin dose at EOT [8, 40, 41, 61-65]. *Statistically significant for non-inferiority. $* *$ Statistically significant for superiority; degludec was capped at 50 units in the DUAL II trial. DUAL VIII data have been excluded as a result of the 104-week durability trial design, which is not directly comparable with the other DUAL studies. $1 W T$ once-weekly titration, $2 W T$ twice-weekly titration, $C I$ confidence interval, EOT end of trial, ERR estimated rate ratio, ETD estimated treatment difference, $G L P-1 R A$ glucagon-like peptide-1 receptor agonist, $H b A_{l c}$ glycated hemoglobin, IAsp insulin aspart, IDegLira insulin degludec/liraglutide, IGlar insulin glargine, $N R$ not reported, $O A D$ oral antidiabetic therapy, PYE participant-year exposure, $U$ units of insulin

\subsection{Insulin-Naïve People Receiving GLP-1RAs in Combination with OADs: IDegLira Compared with GLP-1RA}

The aim of DUAL III, a 26-week, randomized, open-label trial, was to investigate the efficacy of IDegLira in controlling glycemia in adults whose T2D was inadequately controlled on GLP-1RA and OAD therapy (Table 1). Compared with unchanged GLP-1RA therapy, IDegLira was associated with a superior reduction in $\mathrm{HbA}_{1 c}$, a higher rate of hypoglycemia and a mean body weight gain compared with a mean body weight loss (Fig. 1a-c). However, participants treated with IDegLira had a lower rate of GI adverse events than those treated with unchanged GLP-1RA therapy (Table 2) [62].

\subsection{People Receiving Basal Insulin and OADs}

Three trials investigated the efficacy of IDegLira in people switching from a basal insulin regimen (20-40 units or 20-50 units) to IDegLira, compared with continuation with a basal insulin regimen, in combination with metformin, or initiation of a basal-bolus regimen [40, 41, 61].

\subsubsection{DUAL II: IDegLira Compared with Degludec}

DUAL II was a 26-week, randomized, parallel, doubleblind, treat-to-target trial comparing the efficacy and safety of IDegLira with the basal insulin degludec (maximum 50 units), both in combination with metformin (Table 1). All pretrial glucose-lowering drugs were discontinued, except metformin. Participants treated with IDegLira experienced a superior reduction in $\mathrm{HbA}_{1 \mathrm{c}}$ compared with those treated with degludec (Fig. 1a). Furthermore, participants treated with IDegLira experienced a similar rate of confirmed hypoglycemia compared with degludec (Fig. 1b), and there was one severe hypoglycemic event in DUAL II, in a participant

Table 2 Gastrointestinal adverse events in participants in the DUAL clinical trial program

\begin{tabular}{|c|c|c|c|c|c|}
\hline $\begin{array}{l}\text { Previous treatment } \\
\text { regimen }\end{array}$ & DUAL trial & Treatment group & $\begin{array}{l}\text { Nausea (events per } \\
100 \text { PYE) }\end{array}$ & $\begin{array}{l}\text { Diarrhea (events per } \\
100 \text { PYE) }\end{array}$ & $\begin{array}{l}\text { Vomiting } \\
\text { (events per } 100 \\
\text { PYE) }\end{array}$ \\
\hline \multirow[t]{11}{*}{$\mathrm{OAD}(\mathrm{s})$} & \multirow[t]{3}{*}{ DUAL I } & IDegLira & 20.9 & 23.5 & 10.1 \\
\hline & & Degludec & 8.8 & 10.3 & 3.1 \\
\hline & & Liraglutide & 54.3 & 39.8 & 23.6 \\
\hline & \multirow[t]{2}{*}{ DUAL IV } & IDegLira & 11.3 & 10.5 & 5.3 \\
\hline & & Placebo & 8.0 & 12.9 & 6.4 \\
\hline & \multirow[t]{2}{*}{ DUAL VI } & IDegLira 1WT & 13.1 & 4.9 & 3.3 \\
\hline & & IDegLira 2WT & 15.7 & 5.5 & 3.1 \\
\hline & \multirow[t]{2}{*}{ DUAL VIII } & IDegLira & 4.9 & 6.4 & 2.9 \\
\hline & & IGlar U100 & 1.4 & 2.2 & 1.7 \\
\hline & \multirow[t]{2}{*}{ DUAL IX } & IDegLira & 21.3 & 12.6 & 4.8 \\
\hline & & IGlar U100 & 1.9 & 7.6 & 3.8 \\
\hline \multirow[t]{2}{*}{ GLP-1RA } & \multirow[t]{2}{*}{ DUAL III } & IDegLira & 7.8 & 12.8 & 2.8 \\
\hline & & Pre-trial liraglutide or exenatide & 10.6 & 13.7 & 9.1 \\
\hline \multirow[t]{6}{*}{ Basal insulin } & \multirow[t]{2}{*}{ DUAL II } & IDegLira & 21.8 & 22.8 & 9.8 \\
\hline & & Degludec & 7.8 & 8.9 & NR \\
\hline & \multirow[t]{2}{*}{ DUAL V } & IDegLira & 26.2 & 17.7 & 17.0 \\
\hline & & IGlar U100 & 2.2 & 7.4 & 3.7 \\
\hline & \multirow[t]{2}{*}{ DUAL VII } & IDegLira & 30.7 & 19.9 & 10.0 \\
\hline & & IGlar U100+ IAsp ( $\leq 4$ times) & 3.4 & 14.2 & 5.9 \\
\hline
\end{tabular}

$1 W T$ once-weekly titration, $2 W T$ twice-weekly titration, GLP-1RA glucagon-like peptide-1 receptor agonist, IAsp insulin aspart, IDegLira insulin degludec/liraglutide, IGlar insulin glargine, $N R$ not reported, $O A D$ oral antidiabetic therapy, $P Y E$ participant-year exposure 
receiving IDegLira. The rate of nocturnal hypoglycemia observed in participants treated with IDegLira did not differ between groups, nor did the total EOT insulin dose between the degludec monotherapy and IDegLira treatment arms in this dose-capped study (Fig. 1d). IDegLira was associated with an average decrease in body weight compared with no change in body weight with degludec (Fig. 1c) [61].

\subsubsection{DUAL V: IDegLira Compared with IGlar U100}

DUAL V was a 26-week, randomized, treat-to-target trial that compared the efficacy of IDegLira and IGlar U100 in individuals who had insufficient glycemic control while taking metformin and IGlar U100 (20-50 U) (Table 1). Participants randomized to IGlar U100 started the trial on their pretrial dose and uptitrated their treatment over the course of the trial, as required. Participants treated with IDegLira experienced a superior reduction in mean $\mathrm{HbA}_{1 \mathrm{c}}$ compared with IGlar U100 uptitration (Fig. 1a), while participants treated with IDegLira had significantly fewer episodes of confirmed hypoglycemia than those treated with the comparator (Fig. 1b). Only one participant who was receiving IGlar U100 experienced severe hypoglycemia in DUAL V. Participants treated with IDegLira were statistically significantly at less risk of experiencing confirmed nocturnal hypoglycemia than people treated with IGlar U100. There was a significant reduction in the total daily insulin dose, and participants in the IDegLira group experienced body weight loss compared with those in the IGlar U100 group, who experienced body weight gain (Fig. 1c, d) [41].

\subsubsection{DUAL VII: IDegLira Compared with Multiple Daily Insulin Injections (MDIs)}

DUAL VII was a 26-week, open-label, two-arm parallel, randomized, treat-to-target trial. It investigated the efficacy and safety of IDegLira compared with multiple daily insulin injections (MDIs; basal insulin IGlar U100 combined with bolus insulin aspart [IAsp] $\leq 4$ times daily), in people with T2D not reaching their glycemic targets with basal insulin (Table 1). Participants experienced similar reductions in $\mathrm{HbA}_{1 \mathrm{c}}$ in both the IGlar U100 and IAsp and IDegLira treatment arms (Fig. 1a). Participants treated with IDegLira had significantly fewer episodes of confirmed hypoglycemia than those treated with the comparator (Fig. 1b). Furthermore, participants treated with IDegLira had fewer episodes of severe hypoglycemia and nocturnal hypoglycemia compared with IGlar U100 and IAsp. Participants treated with IDegLira were receiving a significantly lower insulin dose at EOT than those treated with IGlar U100 and IAsp (Fig. 1c). IDegLira was also associated with body weight loss compared with body weight gain in the IGlar U100 and IAsp arm (Fig. 1d) [40].

\subsection{People Not Tolerating MDI Regimens}

While the efficacy of IDegLira has been compared with MDIs in the DUAL VII trial, the efficacy of switching from an MDI regimen to an IDegLira regimen has not yet been investigated in a clinical trial setting. However, real-world data have demonstrated the effectiveness of IDegLira in individuals who had switched from MDIs.

The EXTRA study, a real-world retrospective chart review, collected data on 173 people receiving MDIs \pm OADs who switched to treatment with IDegLira [68]. Over 6 months of treatment, these people had a mean $0.7 \%$ ( $8 \mathrm{mmol} / \mathrm{mol}$ ) reduction in $\mathrm{HbA}_{1 \mathrm{c}}$ (from $8.3 \%$ [67 mmol $/ \mathrm{mol}]$ to $7.6 \%$ [60 mmol $/ \mathrm{mol}] ; p<0.0001)$, which was accompanied by a $31 \%$ reduction in daily insulin dose (from 65 units to 45 units; $p<0.0001$ ), and a $2.4-\mathrm{kg}$ decrease in body weight (from a baseline of $102.3 \mathrm{~kg} ; p<0.0001$ ) [68]. This observational study suggests that people switching to IDegLira from an MDI regimen can avoid the inconvenience of multiple daily injections, reducing total daily insulin dose in addition to experiencing beneficial changes in body weight and $\mathrm{HbA}_{1 \mathrm{c}}$.

\subsection{Cardiovascular (CV) Safety}

US FDA guidelines [69] require an assessment of cardiovascular (CV) safety for all new diabetes drugs. Although a CV outcome trial (CVOT) has not been conducted in people treated with IDegLira, CVOTs have been conducted on the individual components: degludec (DEVOTE [33]) and liraglutide (LEADER [70]). DEVOTE demonstrated that degludec was non-inferior to glargine with respect to the incidence of major CV events (MACE) in participants with T2D at high risk for $\mathrm{CV}$ events $(n=7637)$ [33]. A post hoc analysis of participants in DEVOTE, which compared outcomes between participants concomitantly treated with liraglutide with those who had no liraglutide use, found that participants treated with degludec or IGlar U100 with liraglutide had significantly fewer MACE compared with participants in the degludec/IGlar U100 without liraglutide group (hazard ratio [HR] $0.62,95 \%$ CI $0.41 ; 0.92 ; p=0.02$ [71]). This observation suggested that liraglutide might have CV benefits for people treating their T2D with basal insulin.

The LEADER trial demonstrated that participants with T2D at high risk for $\mathrm{CV}$ disease $(n=9340)$ receiving subcutaneous injections of liraglutide $1.8 \mathrm{mg}$ had a lower risk of $\mathrm{CV}$ events and death from any cause than those receiving placebo [70]. Results of a post hoc analysis of LEADER 
that compared participants receiving no insulin treatment, basal-only insulin, or other insulin in addition to liraglutide suggest that the relative cardioprotection of liraglutide (compared with placebo) is preserved, at least in participants also using basal insulin; however, it should be noted that the study was not designed and powered for these post hoc analyses [72].

In addition to the DEVOTE and LEADER trials, further information on the effect of IDegLira on known CV risk factors beyond blood glucose has been provided by post hoc analyses of the DUAL II, V, and VII studies [73]. These analyses found that participants treated with IDegLira experienced a greater decrease in mean systolic blood pressure, consistently lower or equal levels of low-density lipoprotein (LDL), and a small but statistically significant increase in heart rate, compared with the basal insulin comparators. In the DUAL II trial, no differences between treatments were seen for highsensitivity C-reactive protein, whereas apolipoprotein B and brain natriuretic peptide were significantly lower with IDegLira compared with degludec after 26 weeks [73].

Taken together, these data indicate that IDegLira is associated with a general improvement in $\mathrm{CV}$ risk markers compared with basal insulin or basal-bolus therapy [73].

Key clinical learning The components of IDegLira have confirmed non-inferiority (degludec compared with IGlar U100) and superiority (liraglutide compared with placebo), in terms of incidence of MACE in their respective CVOTs $[33,70]$. Additionally, there is evidence of a general improvement in CV risk markers in people treated with IDegLira compared with participants treated with basal insulin [73].

\section{Cost-Effectiveness Analysis of IDegLira}

The cost effectiveness of treatment interventions is a key consideration when choosing therapies for people with T2D. Direct comparison of the acquisition costs of different therapies is insufficient to inform healthcare payer decision making as there are multiple factors to consider aside from achieving glycemic control, including the likelihood and burden of adverse events such as hypoglycemia and body weight gain, quality of life, and, importantly, the prognosis for diabetes-related micro- and macrovascular complications [74-76].

Short- and long-term cost-effectiveness analyses of IDegLira in comparison with uptitration of IGlar U100 and basal-bolus therapy of IGlar U100 and IAsp, have been conducted [74-79]. Based on clinical trial data from both the US and the UK, IDegLira has been shown to provide a cost-effective treatment option in people with uncontrolled T2D (Table 3) [74-79]. In the analyses where IDegLira was associated with increased costs, incremental costeffectiveness ratios remained well below the US valuebased price benchmark of $\$ 100,000-\$ 150,000$ per qualityadjusted life-year (QALY) gained suggested by the Institute for Clinical and Economic Review, or the commonly accepted willingness-to-pay threshold of $£ 20,000-£ 30,000 /$ QALY in the UK (Table 3). The short-term cost of control analyses (cost per person achieving treatment targets) have reported lower or equivalent annual costs of control with IDegLira in comparison with basal-bolus therapy or basal insulin uptitration, both for glycemic targets $\left(\mathrm{HbA}_{1 \mathrm{c}} \leq 6.5 \%\right.$ [ $\leq 48 \mathrm{mmol} / \mathrm{mol}]$ or $<7.0 \%$ [ $<53 \mathrm{mmol} / \mathrm{mol}]$ ) singularly and for composite endpoints without hypoglycemia and/or

Table 3 Treatment costs associated with IDegLira compared with basal or basal-bolus insulin regimens

\begin{tabular}{|c|c|c|c|c|}
\hline Treatments & $\begin{array}{l}\text { Annual per participant } \\
\text { difference in costs }(\$)^{\mathrm{a}}\end{array}$ & $\begin{array}{l}\text { Total cost savings over a } \\
\text { participant's lifetime }\end{array}$ & $\begin{array}{l}\text { ICER (life expectancy) } \\
\text { per life-year gained }\end{array}$ & $\begin{array}{l}\text { ICER (quality-adjusted life } \\
\text { expectancy) per QALY } \\
\text { gained }\end{array}$ \\
\hline \multicolumn{5}{|c|}{ IDegLira compared with uptitrated IGlar U100 } \\
\hline Davies et al. 2016 [78] & - & $£ 1441$ & $£ 7130$ & $£ 6090$ \\
\hline Hunt et al. 2017 [74] & - & $\$ 16,970$ & $\$ 96,039$ & $\$ 63,678$ \\
\hline Hunt et al. 2017 [75] & $\$ 3546$ & - & - & - \\
\hline \multicolumn{5}{|c|}{ IDegLira compared with IGlar U100+IAsp } \\
\hline Davis et al. 2016 [78] & - & $£ 1698$ & IDegLira dominant & IDegLira dominant \\
\hline Dempsey et al. 2018 [77] & - & $\$ 3571$ & IDegLira dominant & IDegLira dominant $\left[\$ 4050^{b}\right]$ \\
\hline Dempsey et al. 2018 [77] & $-\$ 743.44\left[+\$ 267.97^{\mathrm{a}}\right]$ & - & - & IDegLira dominant [ $\left.\$ 2211^{\mathrm{b}}\right]$ \\
\hline Drummond et al. 2018 [76] & $+£ 303\left[+£ 794^{\mathrm{a}}\right]$ & - & - & $£ 5924\left[£ 15,505^{\mathrm{b}}\right]$ \\
\hline
\end{tabular}

IAsp insulin aspart, IDegLira insulin degludec/liraglutide, IGlar insulin glargine, $Q A L Y$ quality-adjusted life-year, ICER incremental cost-effectiveness ratio, $S M B G$ self-measured blood glucose

${ }^{\text {a }}$ Total annual treatment cost, unless stated otherwise

${ }^{\mathrm{b}}$ Values derived from sensitivity analysis in which needle and SMBG costs were excluded 


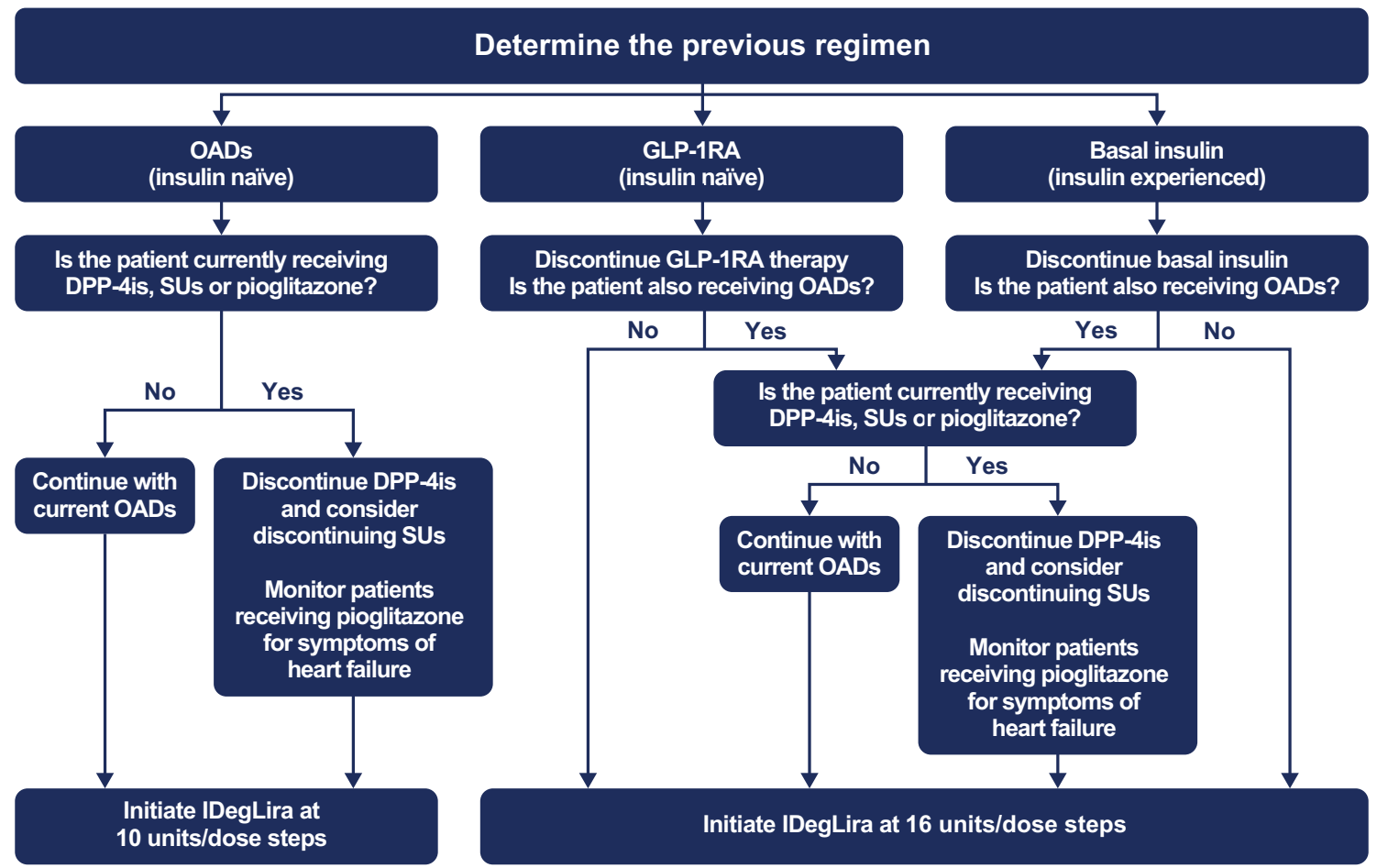

Fig. 2 IDegLira initiation algorithm to provide guidance for physicians based on prior therapy of individuals with T2D. DPP-4i dipeptidyl peptidase 4 inhibitor, $G L P-1 R A$ glucagon-like peptide-1 receptor

body weight gain $[75,79]$. For example, in an analysis of the full DUAL $\mathrm{V}$ trial population, the annual cost per participant achieving a target of $\mathrm{HbA}_{1 \mathrm{c}} \leq 6.5 \%(48 \mathrm{mmol} / \mathrm{mol})$ was lower with IDegLira than with continued uptitration of IGlar U100 (\$18,556 compared with \$21,862); however, the cost per participant achieving $\mathrm{HbA}_{1 \mathrm{c}}<7.0 \%(53 \mathrm{mmol} /$ mol) was similar in the two arms $(\$ 14,358$ compared with $\$ 14,327)$ [75].

\section{Use of IDegLira in Clinical Practice}

\subsection{Initiation}

IDegLira is given as a once-daily subcutaneous injection, which can be administered at any time of the day, but preferably around the same time each day [7]. People not reaching glycemic targets while receiving OADs, GLP-1RAs, and basal insulin can successfully switch to IDegLira, as described in the DUAL trials [8, 40, 41, 61-63, 65] (Fig. 1).

The people who may benefit from a GLP-1RA and basal insulin FRC therapy based on our expert opinion are described in Panel 2, while information on how best to initiate IDegLira is provided in Fig. 2. agonist, IDegLira insulin degludec/liraglutide, $O A D$ oral antidiabetic drug, $S U$ sulfonylurea

Panel 2: Clinical Profiles for People with T2D and Consideration for use of GLP-1RA/Basal Insulin FRC Therapy

We recommend GLP-1RA/basal insulin FRCs such as IDegLira be considered as a first injectable therapy for people with T2D

GLP-1RA/basal insulin FRCs should also be considered as an alternative for people with T2D not reaching their glycemic targets when treated with:

- GLP-1RA monotherapy

- Basal insulin-in people who might otherwise require intensification with MDIs

- Twice-daily basal insulin —in people with recurrent hypoglycaemia - MDIs ${ }^{\mathrm{a}}$

${ }^{\mathrm{a}}$ The use of IDegLira in people with T2D receiving MDIs is not approved and has not been investigated in a clinical trial

$H b A_{l c}$, glycated hemoglobin, $F R C$ fixed ratio combination, GLP-1RA glucagon-like peptide-1 receptor agonists, IDegLira insulin degludec/liraglutide, $M D I$ s multiple daily insulin injections, $T 2 D$ type 2 diabetes

\subsubsection{Addition of IDegLira for People Not Reaching Targets While Taking OADs}

IDegLira is licensed in Europe and the US as an addition to $\mathrm{OAD}$ for people not reaching glycemic targets $[7,66]$. 
In these people, IDegLira should be initiated at 10 units/ dose steps.

Most OADs can be continued when initiating IDegLira without modification. DPP-4 inhibitors are not contraindicated in people initiating IDegLira [7, 66]; however, the combination of DPP-4 inhibitors with GLP-1RAs has no observed clinical benefit [80] and therefore we recommend discontinuation of DPP-4 inhibitors when initiating IDegLira.

People can continue treatment with pioglitazone when initiating IDegLira, but it is important to note that cases of cardiac failure have been reported when pioglitazone has been combined with insulin products, particularly in people with $\mathrm{CV}$ risk factors. Therefore, if pioglitazone is continued when IDegLira is initiated, these individuals should be closely monitored for symptoms of heart failure, body weight gain, and edema. If any of these symptoms or signs occur, pioglitazone should be discontinued [7].

Sulfonylureas can be continued in individuals when IDegLira is initiated, as demonstrated by the DUAL IV trial that assessed the efficacy and safety of IDegLira in people with T2D as an add-on to pretrial sulfonylurea (with or without metformin; Table 1 [63]); however, a reduction in dose and a plan to discontinue should be considered for those close to their glycemic target to reduce the risk of hypoglycemia and body weight gain associated with combining basal insulin or GLP-1RAs with sulfonylureas [7, 36]. A post hoc analysis of the DUAL II trial grouped participants by pretrial sulfonylurea use to investigate glycemic control in those who switched to IDegLira. This analysis demonstrated that participants who discontinued sulfonylureas and initiated IDegLira experienced no loss of glycemic control in the weeks after switching to IDegLira, and reached good glycemic control by week 26 regardless of pretrial sulfonylurea use [81]. While the rates of hypoglycemia were higher in people treated with IDegLira and sulfonylureas concurrently compared with placebo, the rate was the same order of magnitude as recorded in other studies where people were treated concomitantly with sulfonylureas and basal insulin [45, 65, 82]. Clinicians should always consider stopping sulfonylurea therapy when combining with insulin, particularly when treatment with IDegLira is initiated.

Key clinical learning Most OADs can be continued when initiating IDegLira without modification; however, we recommend the discontinuation of DPP-4 inhibitors and a reduction in the dose of sulfonylureas, as well as a plan for discontinuation, when initiating IDegLira. People receiving pioglitazone treatment should be closely monitored for edema and heart failure when initiating IDegLira.

\subsubsection{Switching from GLP-1RA or Basal Insulin to IDegLira}

Prior basal insulin or GLP-1RA therapy should be discontinued prior to the initiation of IDegLira. The recommended starting dose of IDegLira in this group of people is 16 units/dose steps (16 units degludec and $0.6 \mathrm{mg}$ liraglutide) [7, 66]. Although 16 units/dose steps of IDegLira is likely to be a decrease in the total daily insulin dose in people transferring from basal insulin, because of the complementary actions of the two components, glycemic control can be achieved at a lower insulin dose [8]. Furthermore, it is simple to titrate the dose of IDegLira, if necessary.

A post hoc analysis of the DUAL $\mathrm{V}$ trial investigated participant outcomes by pretrial insulin dose $(20$ to $<30$, 30 to $<40$ and 40 to $\leq 50$ units/day) and demonstrated that, regardless of pretrial dose, participants treated with IDegLira achieved a significantly greater reduction in $\mathrm{HbA}_{1 \mathrm{c}}$ from baseline to EOT, compared with IGlar U100 [83]. There was also no clinically significant increase in self-measured blood glucose (SMBG) in any pretrial dose group when switching to IDegLira, and no withdrawals due to hyperglycemia with IDegLira in the first 8 weeks following the switch [83]. Furthermore, results from a real-world population of people with T2D (92\% of whom were being treated with insulin) demonstrated that switching to IDegLira resulted in improved glucose control and body weight loss [84]. The data from both clinical trials and real-world studies therefore suggest that IDegLira can be an effective and often superior substitution for any basal insulin dose [83, 84]. Additionally, results from DUAL VII demonstrate that in people whose diabetes was not controlled with basal insulin, IDegLira provides comparable $\mathrm{HbA}_{1 \mathrm{c}}$ reductions as basal-bolus insulin, with significantly lower hypoglycemia rates and weight loss compared with weight gain [40]. People requiring basal-bolus insulin can represent a challenging patient population, as initiation and intensification of basal-bolus insulin can have limited success in terms of achieving $\mathrm{HbA}_{1 \mathrm{C}}$ targets, and is often associated with increased rates of hypoglycaemia and increased weight. Furthermore, treatment with IDegLira provides a simple, less burdensome injectable therapy compared with basal-bolus insulin, and this may help with taking medication [85].

HCPs may be concerned that IDegLira has a maximum dose of 50 units/dose steps [7, 66], compared with no maximum doses for IGlar U100 and degludec. However, data from the DUAL studies demonstrate that the majority of participants $(\geq 60 \%)$ treated with IDegLira achieved the $\mathrm{HbA}_{1 \mathrm{c}}$ target of $<7.0 \%(<53 \mathrm{mmol} / \mathrm{mol})$ at $\leq 50$ units/dose steps. Additionally, the EXTRA realworld chart review of people with T2D found that only $67(12 \%)$ people reached or exceeded the maximum dose 
Fig. 3 Twice-weekly dose titration recommendations for IDegLira. ${ }^{\mathrm{a}} \mathrm{FPG}$ measurement must be from the proceeding 3 days. $F P G$ fasting plasma glucose, IDegLira insulin degludec/ liraglutide

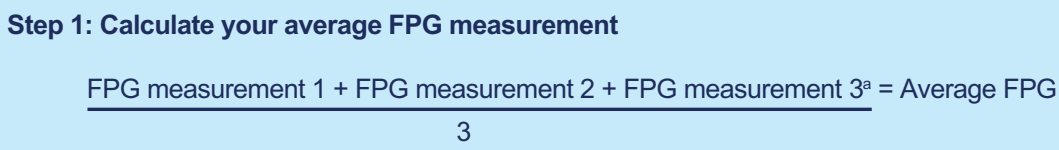

Step 2: Compare your average FPG with the table below, and adjust IDegLira dose as shown

\begin{tabular}{|c|c|c|}
\multicolumn{2}{|c|}{ Fasting self-measured plasma glucose } & \multirow{2}{*}{ Dose adjustment } \\
\cline { 1 - 2 } $\mathrm{mmo} / \mathrm{L}$ & $\mathrm{mg} / \mathrm{dL}$ & $\downarrow$ Decrease by 2 units/dose steps \\
\hline$<4.0$ & $<72$ & Maintain dose \\
\hline $4.0-5.0$ & $72-90$ & $\uparrow$ Increase by 2 units/dose steps \\
\hline$>5.0$ & $>90$ &
\end{tabular}

(50 units/dose steps) of IDegLira either at initiation or at 6 months of follow-up [68].

Key clinical learning People with T2D switching from GLP-1RAs or basal insulin to IDegLira will need to discontinue their prior therapy and initiate IDegLira at 16 units/dose steps. Studies have shown that although this might require a temporary reduction in dose, there was no long-term loss of glycemic control.

\subsubsection{Initiation of IDegLira in People with CV Risk}

There are currently no guidelines that specifically recommend IDegLira in the treatment of people with T2D and CV risk.

The results of several early CVOTs showed that lowering $\mathrm{HbA}_{1 \mathrm{c}}$ has a major beneficial impact on reducing microvascular complications in diabetes, but no clear benefit was seen on macrovascular disease [86-91]. Despite longer-term studies establishing a positive legacy effect of tight glycemic control on CV outcomes [15, 92], an increase in CV mortality was reported in high-risk individuals (those with additional CV risk factors) assigned to intensive glucose control in the ACCORD trial $[90,93]$. Thus, guidelines recommend that targets are individualized to the needs of each person with diabetes and his or her disease factors [19].

The most recent American Diabetes Association (ADA)/ European Association for the Study of Diabetes consensus statement recommends GLP-1RA treatment, particularly liraglutide, as an early step for the intensification of therapy in T2D in people with established atherosclerotic CV disease [3]. It should be noted that this recommendation is based on evidence from the LEADER CVOT, which examined the CV effect of once-daily liraglutide $1.8 \mathrm{mg}$ [70]; thus, it is not yet known if lower doses of liraglutide provide the same CV benefits. If individuals with T2D still do not reach their glycemic targets, the consensus ADA statement recommends further intensification, with the initiation of basal insulin therapy with either degludec or IGlar U100 listed as potential options, as a result of their documented CV safety profiles [3].

\subsection{Titration}

The need for titration is a potential cause of therapeutic inertia and thus a barrier to achievement of good glycemic control. It is important that IDegLira is titrated to a therapeutic dose, but fortunately the titration method is quite simple and does not require carbohydrate counting. It is recommended in the product label that the dose of IDegLira is adjusted twice weekly, in increments of 2 units/dose steps, based on three consecutive FPG readings (Fig. 3) [7, 66]. However, the DUAL VI trial found that once-weekly titration of IDegLira was non-inferior in terms of glycemic control [64], thus offering clinicians and people with diabetes different titration options.

Titration of IDegLira was critical to achieving the glycemic control observed in the DUAL trials. Participants initiated IDegLira at a low dose (10 or 16 units/dose steps, depending on prior therapy $[7,66])$, but reached approximately 40 units/dose steps over the 26- or 32-week trials, and this dose was required to achieve the reported reductions in $\mathrm{HbA}_{1 \mathrm{c}}$. Real-world data from the EXTRA study demonstrated that IDegLira titration in clinical practice is not as aggressive as in the clinical trials, with people with T2D reaching an average dose of 30 units/dose steps after 6 months of treatment, despite starting at a higher dose at initiation, achieving a mean $\mathrm{HbA}_{1 \mathrm{c}}$ of $7.5 \%$ (59 mmol/mol) [68].

The initiation of IDegLira at a low dose, followed by titration, reduces the incidence of GI adverse events usually observed with GLP-1RAs. GI adverse events were a common cause of discontinuation for liraglutide therapy in DUAL I, whereas participants treated with IDegLira were less likely to discontinue as a result of adverse events (5.8\% compared with $1.2 \%$, respectively) [8]. As a result of the need to initiate IDegLira at a low dose, it can take several weeks for individuals with T2D to reach 
their $\mathrm{HbA}_{1 \mathrm{c}}$ targets. The DUAL trials demonstrated that people with T2D can reach their $\mathrm{HbA}_{1 \mathrm{c}}$ target of $<7.0 \%$ $(<53 \mathrm{mmol} / \mathrm{mol})$ at approximately $8-16$ weeks $[8,40,41$, 61-65], at a dose of approximately 40 units/dose steps.

In people with diabetic retinopathy and poor long-term glycemic control, intensification of therapy with insulin has been associated with the worsening of their condition [94]. This risk appears to be associated with rapid reduction of blood glucose levels. Therefore, we think that HCPs should consider less aggressive titration of IDegLira in these people as this may avoid their condition worsening unnecessarily.

Key clinical learning It is important to monitor FPG levels and adjust the dose of IDegLira, in increments of 2 units/ dose steps, to achieve the levels of glycemic control seen in the DUAL trials. However, less aggressive titration may be required in people with diabetic retinopathy and poor longterm glycemic control.

\section{Conclusions}

Therapeutic inertia is a real and ongoing challenge, particularly when initiating and intensifying insulin therapies in people who would benefit from an $\mathrm{HbA}_{1 \mathrm{c}}$ goal of $<7.0 \%$ $(53 \mathrm{mmol} / \mathrm{mol})$. This inertia may in part be due to concerns of people with T2D and HCPs around hypoglycemia, body weight gain, and treatment and titration complexity. Combination therapies, such as IDegLira, offer the opportunity to improve efficacy with better outcomes for body weight and hypoglycemia compared with other insulin-based regimens.

Current guidance recommends the initiation of injectable combinations either as the first injectable in people with $\mathrm{HbA}_{1 \mathrm{c}}>10.0 \%$ (> $86 \mathrm{mmol} / \mathrm{mol}$ ) and/or $2.0 \%$ (22 mmol/ $\mathrm{mol}$ ) above target, or if people with T2D are not reaching $\mathrm{HbA}_{1 \mathrm{c}}$ targets on monotherapy. The DUAL clinical trial program demonstrated the efficacy and safety of IDegLira not only compared with GLP-1RA monotherapy but also compared with basal insulin and basal-bolus therapy regardless of prior insulin therapy. In a real-world setting, the EXTRA study also found that people treated with IDegLira for 6 months experienced improvements in clinical endpoints compared with the beginning of the study. While there was a lower reduction in $\mathrm{HbA}_{1 \mathrm{c}}$ than recorded in the DUAL program, this may be due to the treatment regimen not being followed as rigorously in a real-world setting, as has been demonstrated previously [95].

We recommend that FRCs, such as IDegLira, are considered as a first injectable therapy for people with T2D, and as a superior alternative to the traditional basal-bolus approach for optimizing glycemic control in individuals not reaching their targets on basal insulin. IDegLira should be initiated at 10 units/dose steps unless the individual is already taking insulin, in which case 16 units/dose steps is recommended. The dose should then be titrated by 2 units/ dose steps twice weekly until the individual reaches his or her glycemic target.

Overall, the benefits of consistently improved glycemic control, fewer GI adverse events (than GLP-1RA monotherapy), a lower incidence of hypoglycemia and body weight loss or neutrality (compared with body weight gain seen with insulin), combined with a simple treatment regimen and a durable effect, indicate that IDegLira may help overcome therapeutic inertia and improve medication adherence in people with T2D, thereby leading to better long-term diabetes control. The evidence suggests that IDegLira may provide a more suitable treatment option than insulin alone for individuals at increased risk of hypoglycemia, or concerned about the body weight gain associated with an insulin (basal or basal-bolus) regimen.

Acknowledgements The authors thank Kerry Guest, Ph.D., and Germanicus Hansa-Wilkinson, MSc (Watermeadow Medical, an Ashfield Company, part of UDG Healthcare plc.), for providing medical writing and editorial support. This support was funded by Novo Nordisk.

Author contributions All authors confirm that they meet the International Committee of Medical Journal Editors requirements for authorship and that they have contributed to the conception of the work, drafting and/or critically revising the article, and sharing in the final responsibility for the content of the manuscript and the decision to submit the manuscript for publication.

\section{Compliance with ethical standards}

Conflict of interest Stewart Harris has received fees as a consultant for AstraZeneca, Boehringer Ingelheim, Eli Lilly, Janssen, Medtronic, Merck \& Co, Novo Nordisk, and Sanofi; for research support for the Juvenile Diabetes Research Foundation, the Canadian Institutes of Health Research, the Lawson Foundation, Novo Nordisk, Sanofi, AstraZeneca, and Health Canada/First Nations and Inuit Health Branch; and as an advisory board member for the Juvenile Diabetes Research Foundation, the Canadian Institutes of Health Research, the Lawson Foundation, Novo Nordisk, Sanofi, AstraZeneca, and Health Canada/ First Nations and Inuit Health Branch. Martin J. Abrahamson has received consulting fees or honoraria from Novo Nordisk and Web MD Health Services. Antonio Ceriello has been an advisory board member for AstraZeneca, Boehringer Ingelheim, DOC Generici, Eli Lilly, Janssen, Mundipharma, Novo Nordisk, and OM Pharma; given lectures for Boehringer Ingelheim, Eli Lilly, Mundipharma, Novartis, Novo Nordisk, Sanofi, and Takeda; and received research grants from AstraZeneca, Eli Lilly, Mitsubishi, and Novartis. Marc Evans has received consulting fees or honoraria from Novo Nordisk, NAPP, MSD, AstraZeneca, Sunovion, and Novartis; and lecture/speaker bureau fees from Novo Nordisk, NAPP, Mundipharma, AstraZeneca, MSD, Sunovion, and Novartis. Roger Lehmann has received honoraria for advisory boards from Eli Lilly, Sanofi, MSD, Novo Nordisk, Roche, Medtronic, and Boehringer-Ingelheim; and fees for lecturing, consultancy work, and attendance at conferences from AstraZeneca, Boehringer Ingelheim, Eli Lilly, MSD, Novo Nordisk, and Sanofi. Guillaume Charpentier has received consulting and lecture/speaker bureau fees from Novo Nordisk. Richard Holt has received grants from Novo Nordisk as an investigator on clinical trials; consulting fees or honorarium from Mylan and Novo Nordisk; payment for lectures/speaker's bureau from AstraZeneca, Boehringer Ingelheim, Eli Lilly, Janssen, Lundbeck, Novo 
Nordisk, Otsuka, Sanofi, and Sunovion; and royalties from Wiley as editor-in-chief of Diabetic Medicine and the 5th Edition of the Textbook of Diabetes. Nóra Hosszúfalusi has received consulting fees or honoraria from AstraZeneca, Eli Lilly, and Novo Nordisk; support for travel from Novo Nordisk and 77 Elektronika Hungary; and payment for lectures/speaker's bureaus from Novo Nordisk, Eli Lilly, AstraZeneca, Berlin-Chemie, Boehringer Ingelheim, and Sanofi Aventis. Sultan Linjawi received payment for lectures/speaker's bureau for Novartis. Guy Rutten has received fees as a member of a global advisory board from Novo Nordisk. Andreas Liebl has received fees for consulting from Boehringer Ingelheim, DexCom, Lilly, Medtronic, MSD, Novo Nordisk, and Roche; travel support from Boehringer Ingelheim, Novo Nordisk, and Sanofi; and payment for lectures/speaker's bureau from AstraZeneca, Bayer, Becton Dickinson, Boehringer Ingelheim, Bristol Myers Squibb, DexCom, Medtronic, MSD, Novo Nordisk, OmniaMed, Roche, and Sanofi. Tina Vilsbøll declares personal fees from Amgen, Boehringer Ingelheim, Eli Lilly, AstraZeneca, Merck Sharp \& Dohme, Sanofi, Sun Pharmaceuticals, Novo Nordisk, and BristolMyers Squibb, and grants (to her institution) from Eli Lilly, Boehringer Ingelheim, and Novo Nordisk.

Open Access This article is licensed under a Creative Commons Attribution-NonCommercial 4.0 International License, which permits any non-commercial use, sharing, adaptation, distribution and reproduction in any medium or format, as long as you give appropriate credit to the original author(s) and the source, provide a link to the Creative Commons licence, and indicate if changes were made. The images or other third party material in this article are included in the article's Creative Commons licence, unless indicated otherwise in a credit line to the material. If material is not included in the article's Creative Commons licence and your intended use is not permitted by statutory regulation or exceeds the permitted use, you will need to obtain permission directly from the copyright holder. To view a copy of this licence, visit http://creativecommons.org/licenses/by-nc/4.0/.

\section{References}

1. Kahn SE. The relative contributions of insulin resistance and beta-cell dysfunction to the pathophysiology of type 2 diabetes. Diabetologia. 2003;46(1):3-19.

2. American Diabetes Association. 9. Pharmacologic approaches to glycemic treatment: standards of medical care in diabetes 2018 . Diabetes Care. 2019;42(Suppl 1):S90-102.

3. Davies MJ, D'Alessio DA, Fradkin J, Kernan WN, Mathieu C, Mingrone G, et al. Management of hyperglycemia in type 2 diabetes, 2018. A consensus report by the American Diabetes Association (ADA) and the European Association for the Study of Diabetes (EASD). Diabetes Care. 2018;41(12):2669-701.

4. Nuffer W, Guesnier A, Trujillo JM. A review of the new GLP-1 receptor agonist/basal insulin fixed-ratio combination products. Ther Adv Endocrinol Metab. 2018;9(3):69-79.

5. Anderson SL, Trujillo JM. Basal insulin use with GLP-1 receptor agonists. Diabetes Spectr. 2016;29(3):152-60.

6. Harris SB. The power of two: an update on fixed-dose combinations for type 2 diabetes. Expert Rev Clin Pharmacol. 2016;9(11):1453-62.

7. Novo Nordisk. Xultophy ${ }^{\circledR}$ summary of product characteristics. 2018. https://www.medicines.org.uk/emc/product/3469. Accessed July 2018

8. Gough SC, Bode B, Woo V, Rodbard HW, Linjawi S, Poulsen P, et al. Efficacy and safety of a fixed-ratio combination of insulin degludec and liraglutide (IDegLira) compared with its components given alone: results of a phase 3, open-label, randomised, 26-week, treat-to-target trial in insulin-naive patients with type 2 diabetes. Lancet Diabetes Endocrinol. 2014;2(11):885-93.

9. Gough SC, Bode BW, Woo VC, Rodbard HW, Linjawi S, Zacho $\mathrm{M}$, et al. One-year efficacy and safety of a fixed combination of insulin degludec and liraglutide in patients with type 2 diabetes: results of a 26-week extension to a 26-week main trial. Diabetes Obes Metab. 2015;17(10):965-73.

10. Rosenstock J, Aronson R, Grunberger G, Hanefeld M, Piatti P, Serusclat $\mathrm{P}$, et al. Benefits of LixiLan, a titratable fixed-ratio combination of insulin glargine plus lixisenatide, versus insulin glargine and lixisenatide monocomponents in type 2 diabetes inadequately controlled on oral agents: the LixiLan-O randomized trial. Diabetes Care. 2016;39(11):2026-35.

11. Vijan S, Hayward RA, Ronis DL, Hofer TP. Brief report: the burden of diabetes therapy: implications for the design of effective patient-centered treatment regimens. J Gen Intern Med. 2005;20(5):479-82.

12. Vedtofte L, Knop FK, Vilsboll T. Efficacy and safety of fixedratio combination of insulin degludec and liraglutide (IDegLira) for the treatment of type 2 diabetes. Expert Opin Drug Saf. 2017;16(3):387-96.

13. Pan F, Chernew ME, Fendrick AM. Impact of fixed-dose combination drugs on adherence to prescription medications. J Gen Intern Med. 2008;23(5):611-4.

14. Williams B, Shaw A, Durrant R, Crinson I, Pagliari C, de Lusignan S. Patient perspectives on multiple medications versus combined pills: a qualitative study. QJM. 2005;98(12):885-93.

15. Holman RR, Paul SK, Bethel MA, Matthews DR, Neil HA. 10-year follow-up of intensive glucose control in type 2 diabetes. N Engl J Med. 2008;359(15):1577-89.

16. Ali MK, Bullard KM, Saaddine JB, Cowie CC, Imperatore G, Gregg EW. Achievement of goals in U.S. diabetes care, 19992010. N Engl J Med. 2013;368(17):1613-24.

17. Lipska KJ, Yao X, Herrin J, McCoy RG, Ross JS, Steinman MA, et al. Trends in drug utilization, glycemic control, and rates of severe hypoglycemia, 2006-2013. Diabetes Care. 2017;40(4):468-75.

18. Pantalone KM, Misra-Hebert AD, Hobbs TM, Ji X, Kong SX, Milinovich A, et al. Clinical inertia in type 2 diabetes management: evidence from a large, real-world data set. Diabetes Care. 2018;41(7):e113-4.

19. American Diabetes Association. 6. Glycemic targets: standards of medical care in diabetes-2018. Diabetes Care. 2018;41(Suppl 1):S55-s64.

20. Khunti K, Wolden ML, Thorsted BL, Andersen M, Davies MJ. Clinical inertia in people with type 2 diabetes: a retrospective cohort study of more than 80,000 people. Diabetes Care. 2013;36(11):3411-7.

21. Khunti K, Damci T, Meneghini L, Pan CY, Yale JF. Study of Once Daily Levemir (SOLVE): insights into the timing of insulin initiation in people with poorly controlled type 2 diabetes in routine clinical practice. Diabetes Obes Metab. 2012;14(7):654-61.

22. Evans ML, Sharplin P, Owens DR, Chamberlain GH, Longman AJ, McEwan P. Insulin usage in type 2 diabetes mellitus patients in UK clinical practice: a retrospective cohort-based analysis using the THIN database. Br J Diabetes Vasc Dis. 2010;10(4):178-82.

23. Calvert MJ, McManus RJ, Freemantle N. Management of type 2 diabetes with multiple oral hypoglycaemic agents or insulin in primary care: retrospective cohort study. Br J Gen Pract. 2007;57(539):455-60.

24. Harris SB, Kapor J, Lank CN, Willan AR, Houston T. Clinical inertia in patients with $\mathrm{T} 2 \mathrm{DM}$ requiring insulin in family practice. Can Fam Physician. 2010;56(12):e418-24.

25. Ross SA. Breaking down patient and physician barriers to optimize glycemic control in type 2 diabetes. Am J Med. 2013;126(9 Suppl 1):S38-48. 
26. Haahr H, Heise T. A review of the pharmacological properties of insulin degludec and their clinical relevance. Clin Pharmacokinet. 2014;53(9):787-800.

27. Heise T, Nosek L, Bottcher SG, Hastrup H, Haahr H. Ultralong-acting insulin degludec has a flat and stable glucoselowering effect in type 2 diabetes. Diabetes Obes Metab. 2012;14(10):944-50.

28. Novo Nordisk. Levemir summary of product characteristics. 2018. https://www.ema.europa.eu/en/documents/product-information/ levemir-epar-product-information_en.pdf. Accessed Oct 2019

29. Heise T, Hermanski L, Nosek L, Feldman A, Rasmussen S, Haahr $H$. Insulin degludec: four times lower pharmacodynamic variability than insulin glargine under steady-state conditions in type 1 diabetes. Diabetes Obes Metab. 2012;14(9):859-64.

30. Heise T, Kaplan K, Haahr HL. Day-to-day and within-day variability in glucose-lowering effect between insulin degludec and insulin glargine $(100 \mathrm{U} / \mathrm{mL}$ and $300 \mathrm{U} / \mathrm{mL})$ : a comparison across studies. J Diabetes Sci Technol. 2018;12(2):356-63.

31. Wysham C, Bhargava A, Chaykin L, de la Rosa R, Handelsman $\mathrm{Y}$, Troelsen LN, et al. Effect of insulin degludec vs insulin glargine U100 on hypoglycemia in patients with type 2 diabetes: the SWITCH 2 randomized clinical trial. JAMA. 2017;318(1):45-56.

32. Lane W, Bailey TS, Gerety G, Gumprecht J, Philis-Tsimikas A, Hansen CT, et al. Effect of insulin degludec vs insulin glargine U100 on hypoglycemia in patients with type 1 diabetes: the SWITCH 1 randomized clinical trial. JAMA. 2017;318(1):33-44.

33. Marso SP, McGuire DK, Zinman B, Poulter NR, Emerson SS, Pieber TR, et al. Efficacy and safety of degludec versus glargine in type 2 diabetes. N Engl J Med. 2017;377(8):723-32.

34. Ratner RE, Gough SC, Mathieu C, Del PS, Bode B, Mersebach $\mathrm{H}$, et al. Hypoglycaemia risk with insulin degludec compared with insulin glargine in type 2 and type 1 diabetes: a preplanned meta-analysis of phase 3 trials. Diabetes Obes Metab. 2013;15(2):175-84.

35. Bailey TS, Pettus J, Roussel R, Schmider W, Maroccia M, Nassr $\mathrm{N}$, et al. Morning administration of $0.4 \mathrm{U} / \mathrm{kg} /$ day insulin glargine $300 \mathrm{U} / \mathrm{mL}$ provides less fluctuating 24-hour pharmacodynamics and more even pharmacokinetic profiles compared with insulin degludec $100 \mathrm{U} / \mathrm{mL}$ in type 1 diabetes. Diabetes Metab. 2018;44(1):15-21.

36. Nordisk N. Victoza ${ }^{\circledR}$ prescribing information. 2017. https://www. accessdata.fda.gov/drugsatfda_docs/label/2017/022341s027lbl. pdf. Accessed Jul 2018.

37. Malm-Erjefalt M, Bjornsdottir I, Vanggaard J, Helleberg H, Larsen U, Oosterhuis B, et al. Metabolism and excretion of the once-daily human glucagon-like peptide- 1 analog liraglutide in healthy male subjects and its in vitro degradation by dipeptidyl peptidase IV and neutral endopeptidase. Drug Metab Dispos. 2010;38(11):1944-53

38. Chang AM, Jakobsen G, Sturis J, Smith MJ, Bloem CJ, An B, et al. The GLP-1 derivative NN2211 restores beta-cell sensitivity to glucose in type 2 diabetic patients after a single dose. Diabetes. 2003;52(7):1786-91.

39. Kapitza C, Bode B, Ingwersen SH, Jacobsen SJ, Poulsen P. Preserved pharmacokinetic exposure and distinct glycemic effects of insulin degludec and liraglutide in IDegLira, a fixed-ratio combination therapy. J Clin Pharmacol. 2015;55(12):1369-77.

40. Billings LK, Doshi A, Gouet D, Oviedo A, Rodbard HW, Tentolouris N, et al. Efficacy and safety of IDegLira versus basal-bolus insulin therapy in patients with type 2 diabetes uncontrolled on metformin and basal insulin: the DUAL VII randomized clinical trial. Diabetes Care. 2018;41(5):1009-16.

41. Lingvay I, Pérez Manghi F, Garcia-Hernandez P, Norwood P, Lehmann L, Tarp-Johansen MJ, et al. Effect of insulin glargine uptitration vs insulin degludec/liraglutide on glycated hemoglobin levels in patients with uncontrolled type 2 diabetes: the DUAL V randomized clinical trial. JAMA. 2016;315(9):898-907.

42. Garber AJ. Liraglutide in oral antidiabetic drug combination therapy. Diabetes Obes Metab. 2012;14(Suppl 2):13-9.

43. Meneghini L, Atkin SL, Gough SC, Raz I, Blonde L, Shestakova $\mathrm{M}$, et al. The efficacy and safety of insulin degludec given in variable once-daily dosing intervals compared with insulin glargine and insulin degludec dosed at the same time daily: a 26-week, randomized, open-label, parallel-group, treat-to-target trial in individuals with type 2 diabetes. Diabetes Care. 2013;36(4):858-64.

44. Gough SC, Bhargava A, Jain R, Mersebach H, Rasmussen S, Bergenstal RM. Low-volume insulin degludec 200 units/ml once daily improves glycemic control similarly to insulin glargine with a low risk of hypoglycemia in insulin-naive patients with type 2 diabetes: a 26-week, randomized, controlled, multinational, treatto-target trial: the BEGIN LOW VOLUME trial. Diabetes Care. 2013;36(9):2536-42.

45. Onishi Y, Iwamoto Y, Yoo SJ, Clauson P, Tamer SC, Park S Insulin degludec compared with insulin glargine in insulinnaive patients with type 2 diabetes: a 26 -week, randomized, controlled, Pan-Asian, treat-to-target trial. J Diabetes Investig. 2013;4(6):605-12.

46. Zinman B, Philis-Tsimikas A, Cariou B, Handelsman Y, Rodbard $\mathrm{HW}$, Johansen $\mathrm{T}$, et al. Insulin degludec versus insulin glargine in insulin-naive patients with type 2 diabetes: a 1-year, randomized, treat-to-target trial (BEGIN Once Long). Diabetes Care. 2012;35(12):2464-71.

47. Repas T. Next-generation GLP-1 therapy: an introduction to liraglutide. Postgrad Med. 2011;123(5):239-47.

48. Bell TJ, Wright EE Jr. Can therapies that target the incretin system improve our ability to treat type 2 diabetes? J Natl Med Assoc. 2010;102(6):511-23.

49. Marre M, Shaw J, Brandle M, Bebakar WM, Kamaruddin NA, Strand J, et al. Liraglutide, a once-daily human GLP-1 analogue, added to a sulphonylurea over 26 weeks produces greater improvements in glycaemic and weight control compared with adding rosiglitazone or placebo in subjects with Type 2 diabetes (LEAD-1 SU). Diabet Med. 2009;26(3):268-78.

50. Nauck M, Frid A, Hermansen K, Shah NS, Tankova T, Mitha IH, et al. Efficacy and safety comparison of liraglutide, glimepiride, and placebo, all in combination with metformin, in type 2 diabetes: the LEAD (liraglutide effect and action in diabetes)-2 study. Diabetes Care. 2009;32(1):84-90.

51. Garber A, Henry R, Ratner R, Garcia-Hernandez PA, RodriguezPattzi H, Olvera-Alvarez I, et al. Liraglutide versus glimepiride monotherapy for type 2 diabetes (LEAD-3 mono): a randomised, 52-week, phase III, double-blind, parallel-treatment trial. Lancet. 2009;373(9662):473-81.

52. Zinman B, Gerich J, Buse JB, Lewin A, Schwartz S, Raskin P, et al. Efficacy and safety of the human glucagon-like peptide-1 analog liraglutide in combination with metformin and thiazolidinedione in patients with type 2 diabetes (LEAD-4 Met+ TZD). Diabetes Care. 2009;32(7):1224-30.

53. Russell-Jones D, Vaag A, Schmitz O, Sethi BK, Lalic N, Antic $\mathrm{S}$, et al. Liraglutide vs insulin glargine and placebo in combination with metformin and sulfonylurea therapy in type 2 diabetes mellitus (LEAD-5 met+ SU): a randomised controlled trial. Diabetologia. 2009;52(10):2046-55.

54. Buse JB, Rosenstock J, Sesti G, Schmidt WE, Montanya E, Brett $\mathrm{JH}$, et al. Liraglutide once a day versus exenatide twice a day for type 2 diabetes: a 26-week randomised, parallel-group, multinational, open-label trial (LEAD-6). Lancet. 2009;374(9683):39-47.

55. Shyangdan DS, Royle PL, Clar C, Sharma P, Waugh NR. Glucagon-like peptide analogues for type 2 diabetes mellitus: systematic review and meta-analysis. BMC Endocr Disord. 2010;10:20. 
56. Vora J, Bain SC, Damci T, Dzida G, Hollander P, Meneghini LF, et al. Incretin-based therapy in combination with basal insulin: a promising tactic for the treatment of type 2 diabetes. Diabetes Metab. 2013;39(1):6-15.

57. Aroda VR, Bailey TS, Cariou B, Kumar S, Leiter LA, Raskin $P$, et al. Effect of adding insulin degludec to treatment in patients with type 2 diabetes inadequately controlled with metformin and liraglutide: a double-blind randomized controlled trial (BEGIN: ADD TO GLP-1 Study). Diabetes Obes Metab. 2016;18(7):663-70.

58. DeVries JH, Bain SC, Rodbard HW, Seufert J, D'Alessio D, Thomsen AB, et al. Sequential intensification of metformin treatment in type 2 diabetes with liraglutide followed by randomized addition of basal insulin prompted by A1C targets. Diabetes Care. 2012;35(7):1446-54.

59. Ahmann A, Rodbard HW, Rosenstock J, Lahtela JT, de Loredo L, Tornoe K, et al. Efficacy and safety of liraglutide versus placebo added to basal insulin analogues (with or without metformin) in patients with type 2 diabetes: a randomized, placebo-controlled trial. Diabetes Obes Metab. 2015;17(11):1056-64.

60. Maiorino MI, Chiodini P, Bellastella G, Scappaticcio L, Longo $\mathrm{M}$, Esposito K, et al. Free and fixed-ratio combinations of basal insulin and GLP-1 receptor agonists versus basal insulin intensification in type 2 diabetes: a systematic review and metaanalysis of randomized controlled trials. Diabetes Obes Metab. 2018;20(9):2309-13.

61. Buse JB, Vilsboll T, Thurman J, Blevins TC, Langbakke IH, Bottcher SG, et al. Contribution of liraglutide in the fixed-ratio combination of insulin degludec and liraglutide (IDegLira). Diabetes Care. 2014;37(11):2926-33.

62. Linjawi S, Bode BW, Chaykin LB, Courreges JP, Handelsman Y, Lehmann LM, et al. The efficacy of IDegLira (insulin degludec/liraglutide combination) in adults with type 2 diabetes inadequately controlled with a GLP-1 receptor agonist and oral therapy: DUAL III randomized clinical trial. Diabetes Ther. 2017;8(1):101-14.

63. Rodbard HW, Bode BW, Harris SB, Rose L, Lehmann L, Jarlov $\mathrm{H}$, et al. Safety and efficacy of insulin degludec/liraglutide (IDegLira) added to sulphonylurea alone or to sulphonylurea and metformin in insulin-naive people with Type 2 diabetes: the DUAL IV trial. Diabet Med. 2017;34(2):189-96.

64. Harris SB, Kocsis G, Prager R, Ridge T, Chandarana K, Halladin N, et al. Safety and efficacy of IDegLira titrated once weekly versus twice weekly in patients with type 2 diabetes uncontrolled on oral antidiabetic drugs: DUAL VI randomized clinical trial. Diabetes Obes Metab. 2017;19(6):858-65.

65. Philis-Tsimikas A, Billings LK, Busch R, Morales Portillo C, Sahay R, Halladin N, et al. Superior efficacy of insulin degludec/ liraglutide versus insulin glargine U100 as add-on to sodiumglucose co-transporter-2 inhibitor therapy: a randomized clinical trial in patients with uncontrolled type 2 diabetes. Diabetes Obes Metab. 2019. https://doi.org/10.1111/dom.13666 (Epub 13 Feb 2019).

66. Novo Nordisk. Xultophy ${ }^{\circledR}$ prescribing information (PI). 2016. https://www.accessdata.fda.gov/drugsatfda_docs/label /2016/208583s0001bl.pdf. Accessed July 2017

67. Aroda VR, Gonzalez-Galvez G, Gron R, Halladin N, Haluzik M, Jermendy G, et al. Durability of insulin degludec plus liraglutide versus insulin glargine U100 as initial injectable therapy in type 2 diabetes (DUAL VIII): a multicentre, open-label, phase $3 b$, randomised controlled trial. Lancet Diabetes Endocrinol. 2019;7(8):596-605.

68. Price H, Bluher M, Prager R, Phan TM, Thorsted BL, Schultes B. Use and effectiveness of a fixed-ratio combination of insulin degludec/liraglutide (IDegLira) in a real-world population with type 2 diabetes: results from a European, multicentre, retrospective chart review study. Diabetes Obes Metab. 2018;20(4):954-62.

69. US Department of Health and Human Services, Food and Drug Administration, Center for Drug Evaluation and Research. Guidance for industry: diabetes mellitus - evaluating cardiovascular risk in new antidiabetic therapies to treat type 2 diabetes. 2008. https://www.fda.gov/downloads/Drugs/Guidances/ucm07 1627.pdf. Accessed Nov 2019.

70. Marso SP, Daniels GH, Brown-Frandsen K, Kristensen P, Mann JF, Nauck MA, et al. Liraglutide and cardiovascular outcomes in type 2 diabetes. N Engl J Med. 2016;375(4):311-22.

71. Brown-Frandsen K, Emerson SS, McGuire DK, Pieber TR, Poulter NR, Pratley RE, et al. Lower rates of cardiovascular events and mortality associated with liraglutide use in patients treated with basal insulin - a DEVOTE subanalysis (DEVOTE 10). Diabetes Obes Metab. 2019;21(6):1437-44.

72. Tack C, Jacob S, Desouza C, Bain SC, Nauck MA, Petrie J, et al. Liraglutide effects in insulin-treated patients in LEADER. Diabetes. 2018;67(Suppl):1.

73. Vilsboll T, Blevins TC, Jodar E, Poulter N, Tentolouris N, Ross Agner BF, et al. Fixed-ratio combination of insulin degludec and liraglutide (IDegLira) improves cardiovascular risk markers in patients with type 2 diabetes uncontrolled on basal insulin. Diabetes Obes Metab. 2019;21(6):1506-12.

74. Hunt B, Mocarski M, Valentine WJ, Langer J. IDegLira versus insulin glargine U100: a long-term cost-effectiveness analysis in the US setting. Diabetes Ther. 2017;8(3):531-44.

75. Hunt B, Mocarski M, Valentine WJ, Langer J. Evaluation of the short-term cost-effectiveness of IDegLira versus continued up-titration of insulin glargine U100 in patients with type 2 diabetes in the USA. Adv Ther. 2017;34(4):954-65.

76. Drummond R, Malkin S, Du Preez M, Lee XY, Hunt B. The management of type 2 diabetes with fixed-ratio combination insulin degludec/liraglutide (IDegLira) versus basal-bolus therapy (insulin glargine U100 plus insulin aspart): a short-term cost-effectiveness analysis in the UK setting. Diabetes Obes Metab. 2018;20(10):2371-8.

77. Dempsey M, Mocarski M, Langer J, Hunt B. Ideglira is associated with improved short-term clinical outcomes and cost savings compared with insulin glargine U100 plus insulin aspart in the U.S. Endocr Pract. 2018;24(9):796-804.

78. Davies MJ, Glah D, Chubb B, Konidaris G, McEwan P. Cost Effectiveness of IDegLira vs. alternative basal insulin intensification therapies in patients with type 2 diabetes mellitus uncontrolled on basal insulin in a UK setting. PharmacoEconomics. 2016;34(9):953-66.

79. Billings LK, Mocarski M, Slothuus U, Hunt B, Valentine W, Jodar E. Evaluation of the short-term cost-effectiveness of insulin degludec/liraglutide (IDegLira) vs basal-bolus therapy in the USA [abstract no. 981-P]. Diabetes. 2017;66(Suppl 1):A254.

80. Nauck MA, Kahle M, Baranov O, Deacon CF, Holst JJ. Addition of a dipeptidyl peptidase-4 inhibitor, sitagliptin, to ongoing therapy with the glucagon-like peptide- 1 receptor agonist liraglutide: a randomized controlled trial in patients with type 2 diabetes. Diabetes Obes Metab. 2017;19(2):200-7.

81. Janez A, Silver R, Vilsbøll T, Grøn R, Halladin N, Örsy P, et al. IDegLira improves glycaemic control in subjects with type 2 diabetes uncontrolled on basal insulin without deterioration despite discontinuing pre-trial sulphonylurea. Diabetologia. 2018;61(Suppl): 1 .

82. Riddle MC, Rosenstock J, Gerich J. Insulin Glargine Study I. The treat-to-target trial: randomized addition of glargine or human NPH insulin to oral therapy of type 2 diabetic patients. Diabetes Care. 2003;26(11):3080-6.

83. Meneghini L, Jaeckel E, Leiter LA, Lingvay I, Harvey JN, Begtrup K, et al. Converting to insulin degludec/liraglutide 
(IDegLira) is efficacious regardless of pretrial insulin dose in patients with type 2 diabetes (T2D) uncontrolled on insulin glargine U100 (IGlar) [abstract no. 1093-P]. Diabetes. 2017;66(Suppl. 1):A289.

84. Sofra D. Glycemic control in a real-life setting in patients with type 2 diabetes treated with IDegLira at a single Swiss center. Diabetes Ther. 2017;8(2):377-84.

85. Pfeiffer KM, Basse A, Lee XY, Waldman LT. Diabetes management and healthcare resource use when intensifying from basal insulin to basal-bolus: a survey of type 2 diabetes patients. Diabetes Ther. 2018;9(5):1931-44.

86. Nathan DM, Genuth S, Lachin J, Cleary P, Crofford O, Davis $\mathrm{M}$, et al. The effect of intensive treatment of diabetes on the development and progression of long-term complications in insulin-dependent diabetes mellitus. N Engl J Med. 1993;329(14):977-86.

87. UK Prospective Diabetes Study (UKPDS) Group. Effect of intensive blood-glucose control with metformin on complications in overweight patients with type 2 diabetes (UKPDS 34). Lancet. 1998;352(9131):854-65.

88. UK Prospective Diabetes Study (UKPDS) Group. Intensive blood-glucose control with sulphonylureas or insulin compared with conventional treatment and risk of complications in patients with type 2 diabetes (UKPDS 33). Lancet. 1998;352(9131):837-53
89. Duckworth W, Abraira C, Moritz T, Reda D, Emanuele $\mathrm{N}$, Reaven PD, et al. Glucose control and vascular complications in veterans with type 2 diabetes. N Engl J Med. 2009;360(2):129-39.

90. Gerstein HC, Miller ME, Byington RP, Goff DC Jr, Bigger JT, Buse JB, et al. Effects of intensive glucose lowering in type 2 diabetes. N Engl J Med. 2008;358(24):2545-59.

91. Patel A, MacMahon S, Chalmers J, Neal B, Billot L, Woodward $\mathrm{M}$, et al. Intensive blood glucose control and vascular outcomes in patients with type 2 diabetes. N Engl J Med. 2008;358(24):2560-72.

92. Hayward RA, Reaven PD, Emanuele NV. Follow-up of glycemic control and cardiovascular outcomes in type 2 diabetes. $\mathrm{N}$ Engl J Med. 2015;373(10):978.

93. ACCORD Study Group. Nine-year effects of 3.7 years of intensive glycemic control on cardiovascular outcomes. Diabetes Care. 2016;39(5):701-8.

94. Feldman-Billard S, Larger É, Massin P. Early worsening of diabetic retinopathy after rapid improvement of blood glucose control in patients with diabetes. Diabetes Metab. 2018;44(1):4-14.

95. Edelman SV, Polonsky WH. Type 2 diabetes in the real world: the elusive nature of glycemic control. Diabetes Care. 2017;40(11):1425-32.

\section{Affiliations}

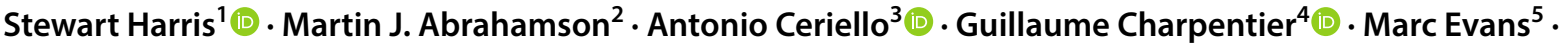

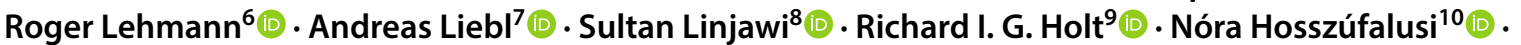 Guy Rutten ${ }^{11} \mathbb{D} \cdot$ Tina Vilsbøll $^{12}$ (D)}

1 Centre for Studies in Family Medicine, Schulich School of Medicine and Dentistry, Western University, WCPHFM, 1151 Richmond St, London, ON N6K 3K7, Canada

2 Division of Endocrinology, Harvard Medical School, Beth Israel Deaconess Medical Center, 110 Francis Street, Lowry 6A, Boston, MA 02215, USA

3 IRCCS MultiMedica, Via Milanese 300, 20099 Sesto San Giovanni, MI, Italy

4 CERITD (Centre d'Etude et de Recherche pour l'Intensification du Traitement du Diabete), Centre Hospitalier Sud Francilien, 1 Rue Pierre Fontaine, 9100 Corbeil-Essonnes, Evry, France

5 Diabetes Resource Centre, University Hospital Llandough, Penlan Road, Llandough, Cardiff CF64 2XX, UK

6 Department of Endocrinology, Diabetology and Clinical Nutrition, University Hospital of Zürich, Rämistrasse 100 (Arrival), 8091 Zürich, Switzerland
7 Center for Diabetes and Metabolism, m\&i-Fachklinik, Woernerweg 30, 83670 Bad Heilbrunn, Germany

8 Coffs Diabetes Centre, 9 Murdock Street, Coffs Harbour, NSW 2450, Australia

9 Human Development and Health, University of Southampton Faculty of Medicine, Southampton, UK

10 3rd Department of Medicine, Semmelweis University, Kútvölgyi út 4, Budapest 1125, Hungary

11 Julius Centre for Health Sciences and Primary Care, University Medical Centre Utrecht, Universiteitsweg 100, 3584 CG Utrecht, The Netherlands

12 Steno Diabetes Center Copenhagen, Gentofte Hospital, University of Copenhagen, Kildegaards Vej 28, 2900 Hellerup, Denmark 